\title{
Bias and size effects of price-comparison platforms: theory and experimental evidence
}

Article

Accepted Version

Garcia Gallego, A., Georgantzis, N., Pereira, P. and PerniasCerrillo, J. C. (2017) Bias and size effects of price-comparison platforms: theory and experimental evidence. Review of Network Economics, 15 (1). pp. 1-34. ISSN 1446-9022 doi: https://doi.org/10.1515/rne-2016-0015 Available at https://centaur.reading.ac.uk/68815/

It is advisable to refer to the publisher's version if you intend to cite from the work. See Guidance on citing.

To link to this article DOI: http://dx.doi.org/10.1515/rne-2016-0015

Publisher: De Gryuter

All outputs in CentAUR are protected by Intellectual Property Rights law, including copyright law. Copyright and IPR is retained by the creators or other copyright holders. Terms and conditions for use of this material are defined in the End User Agreement.

www.reading.ac.uk/centaur 
Central Archive at the University of Reading

Reading's research outputs online 


\title{
Bias and Size Effects of Price-Comparison Platforms: Theory and Experimental Evidence
}

\author{
AURORA GARCÍA-GALLEGO* \\ NIKOLAOS GEORGANTZÍIS ${ }^{\dagger}$ \\ PEDRO PEREIRA \\ JOSÉ C. PERNÍAS-CERRILLO ${ }^{\S}$
}

January, 2017

\begin{abstract}
We analyze the impact on consumer prices of some information characteristics of pricecomparison search platforms. An equilibrium model where vendors compete in prices and consumers do not observe prices, but can obtain price information through a search platform, is developed. The model generates several predictions about the impact on the price distribution of: (i) the size of the search platform's sample, (ii) whether the search platform's sample is random, and (iii) the number of vendors in the market. The model's predictions are tested experimentally. The results confirm the predictions about (ii) and (iii), but reject the model's predictions about (i).
\end{abstract}

Keywords: search platforms, incomplete information, selective information, price competition, experiments.

JEL Codes: C91, D43, D83, L13.

Corresponding author: Prof. Aurora García-Gallego: Dep. Economia, Universitat Jaume I, Av. Sos Baynat, 12071-Castellón (Spain); e-mail: mgarcia@eco.uji.es; phone: 34-964387631.

*LEE, Economics Department, Universitat Jaume I, Castellón (Spain).

${ }^{\dagger}$ School of Agriculture, Policy and Development, University of Reading (UK) and LEE-Economics Dpt., Universitat Jaume I, Castellón (Spain).

$¥$ Autoridade da Concorrência and CEFAGE-UE (Portugal).

${ }^{\S}$ Economics Department, Universitat Jaume I, Castellón (Spain). 


\section{INTRODUCTION}

\subsection{Preliminary Thoughts}

Contrary to the perfect competition paradigm, in many markets, namely retail markets, price information is not freely available to consumers. To the contrary, obtaining price information typically requires some costly action by consumers, like visiting the vendors' premises. Several mechanisms have emerged to address this problem. Firms may advertise their prices to consumers. Alternatively, firms may develop a reputation for having low prices. Or still, third parties may emerge, whose job is to collect and disseminate price information. The impact on consumer prices of some of the characteristics of the information provided by these third parties, to which we will refer as price-comparison search platforms, is the subject of this article.

Price-comparison search platforms are not new and have taken many formats. The Kelley Blue Book for automobiles is a well known example of the many publications that exist dedicated to collecting, comparing and disseminating information on a product's price in industries such as: automobile, consumer electronics, real estate, etc. More recently, the development of the internet allowed the emergence of price-comparison web sites or search engines. ${ }^{1}$ There are now several online platforms covering products like: hotel rooms, airplane tickets or consumer electronics.

Price-comparison search platforms can reduce search costs and enhance the ability of consumers to observe and compare the prices of a large number of vendors. This can discipline vendors, and put downward pressure on prices. $^{2}$ Presumably, the larger the number of vendors whose price a price-comparison search platform lists, and that thereby consumers can compare, the more competitive the market becomes. However, there are several reasons for price-comparison search platforms to cover only a small subset of the market, and to collect and report information favorable to certain vendors. ${ }^{3}$

In many retail markets there is a very large number of active vendors. It is not feasible for a price comparison platform to cover all of them. Usually, the most one can aspire to is to collect a representative sample of prices. In addition, search platforms are profit seeking entities. Hence, depending on the type of clients they cater to, consumers or vendors, pricecomparison platforms will collect and report the type of information that makes them more attractive to their clients.

Consider the case where price-comparison platform are magazines that review consumer products. Some, financed mostly by the cover price, are independent in their evaluations, while others, financed mostly by advertisements, are less independent. Still others, financed both by the cover price and by advertising, may not be completely independent, buy may still have a high level of independence. All of these types of magazines coexist. Well informed consumers can distinguish between the various types magazines. Less informed consumers are probably

1. Price comparison search engines, also known as shopping agents or shopping robots, are a class of search engines, which retrieve, store, and return information, namely about prices, of various products.

2. The search literature has no simple prediction about the relation between search costs, price levels, or price dispersion (Pereira, 2005; Samuelson and Zhang, 1992).

3. For price-comparison search engines see, e.g., Bradlow and Schmittlein (1999) and Lawrence and Giles $(1998,1999)$. 
unable to do so.

Recently, in several jurisdictions, rivals and competition authorities brought various antitrust cases against Google. ${ }^{4}$ More specifically, it was alleged that Google's general search engine lowered the ranking of unpaid search results of competing services, e.g., price comparison shopping services, and gave preferential placement to the results of its own services. This conduct would prevent consumers from seeing the most relevant results to their search queries, and hinder its rivals' ability to compete. In addition, it was also alleged that Google lowered the quality score for sponsored search results of competing services. This would raise the price paid to Google by advertisers. These antitrust cases reinforce the perspective that the distortion information by these platforms is not just a hypothetical possibility.

Several theoretical and empirical papers, which are reviewed below, have studied the impact of individual strategies on prices from both the consumer's and the producer's point of view. However, the impact of the resulting informational patterns (complete vs incomplete or unbiased vs selective coverage) on prices has not been studied in a systematic way. Especially, the robustness of predictions obtained under the assumptions of partial equilibrium search models has not been challenged in the presence of more realistic settings in which agents, rather than optimizing under unlimited calculus ability, they learn through feedback from past actions. We undertake this task here, exposing a sample of participants, to a context closely replicating the conditions of a partial equilibrium model set up to capture the aforementioned cases of complete, incomplete and selective coverage of vendor prices in an oligopolistic market.

\subsection{Overview}

In this article, we examine, theoretically and experimentally, the impact on market prices of some informational features of the sample collected and provided by price-comparison search platforms, namely: (i) the number of vendors covered, and (ii) whether the vendors were picked randomly. In addition, our article also reexamines the impact of the number of vendors in the market on prices, distinguishing between types of consumers.

We develop a partial equilibrium search model, related to Burdett and Judd (1983) and Varian (1980), to discuss the implications of price-comparison search platforms providing consumers with incomplete and selective information. There is: (i) one price-comparison search platform, (ii) a finite number of identical vendors, and (iii) a large number of consumers of two types: searchers and non-searchers. Vendors choose prices. The search platform collects and lists a sample of market prices. Searchers use the search platform, and buy at the lowest listed price. Non-searchers buy from a vendor chosen at random. In equilibrium, vendors randomize between charging a higher price and selling only to non-searchers, and charging a lower price to try to sell also to searchers.

In the benchmark case, the search platform has complete coverage, i.e., lists all vendors. We also analyze two other polar cases on how the sample is chosen. First, the case in which the search platform has incomplete coverage and is unselective, i.e., lists a random subsample

4. E.g., the European Commission, on 30 November 2010, initiated antitrust proceedings against Google in cases COMP/C-3/39.740, COMP/C-3/39.775 \& COMP/C-3/39.768, and on 14 July 2016, initiated antitrust proceedings against Google's mother company Alphabet in case AT.39740. 
of vendors. Second, we analyze the case in which the search platform has incomplete coverage and is selective, i.e., lists a pre-determined subset of vendors.

The theoretical analysis makes several predictions regarding the impact of: (i) the number of vendors sampled by the search platform, (ii) whether the sample of vendors collected by the search platform is random, and (iii) the number of vendors in the market. In addition, the model draws attention to four general counter-intuitive effects. First, there is a conflict of interests between types of consumers, i.e., between searchers and non-searchers. This makes it hard to evaluate the welfare impact of these effects. Second, more information, measured by a wider Internet coverage by the search platform, is not necessarily desirable. It benefits some consumers, but harms others. Third, and for the same reason, unselective information about vendors is not necessarily desirable either. Fourth, the effects of entry in these markets are complex, and depend on the way entry occurs.

We test the model's predictions in a laboratory experiment designed specifically for that purpose. The results confirm the predictions about whether the sample is random, and the impact of the number of active vendor, but reject the predictions about the number of vendors sampled. Moreover, the data analysis indicates several additional patterns, such as that prices are lower under selective than under unselective incomplete coverage.

The intuition of some of these results might clash with the common wisdom about the effects of competition, because our analysis refers to markets where firms play mixed strategies. However, the results related to the impact of the number of rivals on prices apply more broadly and are also present in models where firms play pure strategies, such as those of Bagwell and Lee (2012), Chen and Riordan (2008) and Seade (1980), and documented empirically by Frank and Salkever (1997) and Grabowski and Vernon (1992).

\subsection{Literature Review}

The seminal work of Stigler (1961) drew attention to the importance of price information and search costs for the efficient functioning of markets. This led to the development of several theoretical models, encompassing various types of search behavior and market equilibria. The basic search models relevant for our article were developed in the early 1980s by Burdett and Judd (1983), Varian (1980), Rosenthal (1980) and Stahl (1989). Parallel to this theoretical research there was also extensive empirical research with both field data, e.g., Dahlby and West (1986), Lach (2002) and Sorensen (2002), and experimental data, e.g., Harrison and Morgan (1990) and Schotter and Braunstein (1981).

Several experimental studies have documented the negative relationship between consumer search and price levels, as well as price dispersion resulting from the coexistence of informed and uninformed consumers in the market. Two experiments are of particular interest to our research. Cason and Friedman (2003) conducted a laboratory study of Burdett and Judd (1983)'s model. They used human sellers in all treatments, and human or robot sellers depending on the treatment. They found that overall the data conforms to the theory, especially when the design provided for automated optimal search by consumers, thus reducing the noise from human behavior on both sides of the market. This inspires our design, which also restricts attention to behavior on the supply side, by simulating the demand-side behavior. Morgan et al. (2006) conducted a laboratory study of Varian (1980)'s model. In particular, they evaluated the impact 
of changing the number of firms and the proportion of informed consumers. In all treatments, they used human sellers and robot buyers. They obtained mixed results in terms of the data conforming to the theory. The theoretical predictions concerning the impact of firm number and the proportion of uninformed consumers on equilibrium price distributions were mostly confirmed. However, observed price distributions exhibit systematic deviations from the corresponding equilibrium predictions. 5

The development of the Internet and the emergence of price-comparison search platforms renewed the interest in this subject both from a theoretical perspective, e.g., Arnold et al. (2011), Baye and Morgan (2001), Dinlersoz and Pereira (2007), Ellison and Wolitzky (2012), Iyer and Pazgal (2000) and Janssen and Moraga (2004), and from an empirical perspective, e.g., Brynjolfsson and Smith (2000), Brown and Goolsbee (2002), Clay et al. (2002), Clemons et al. (2002), De los Santos et al. (2013), Ellison and Ellison (2009) and Tang et al. (2010).

Finally, there has also been theoretical research on the impact of the search platform's strategic behavior on market efficiency, e.g., Armstrong et al. (2009), Athey and Ellison (2011), Corniere and Taylor (2012), Hagiu and Jullien (2011) or White (2013). In Varian (1980) some consumers observe one price and others observe all prices. In Burdett and Judd (1983) some consumers observe one price and others observe two prices. In all of these cases the price samples are unbiased. ${ }^{6}$ In our model, the sample of prices that consumers observe: (i) can vary between one and all prices, and (ii) may be unbiased or biased. These characteristics are intended to capture the platform's level of coverage and whether the platform's interests are aligned with some vendors or with consumers. None of these characteristics had been previously examined by the theoretical or experimental literatures.

Hence, our article contributes to the literature by examining, both theoretically and experimentally, the impact on market prices of some informational features of the sample collected and provided by price-comparison search platforms, namely: (i) the number of vendors covered, and (ii) whether the vendors were picked randomly. In addition, our article also reexamines the impact of the number of vendors in the market on prices, distinguishing between types of consumers.

The remainder of the paper is organized as follows. In Section 2 we present the benchmark model, and in Section 3 we characterize its equilibrium. In Section 4 we conduct the analysis of the model and its variations. Section 5 analyzes the results of the experiment. Section 6 concludes. Appendices A and B include, respectively, the proofs and the experimental instructions.

5. Orzen (2008) conducted a laboratory study to determine the impact of repeated interaction on Morgan et al. (2006)'s results, under a fixed-matching protocol. He found that repeated interaction leads to prices above those predicted by the model in small oligopolies, but does not in larger oligopolies.

6. In Varian (1980) there are finite number of identical firms and a continuum of two types of consumers. Searchers, can observe all prices at zero cost, while non-searchers, observe only one price. Firms randomize between charging low prices to try to sell to searchers, and charging high prices to sell only to their share of nonsearchers. In Burdett and Judd (1983) there is a continuum of identical firms and a continuum identical consumers. With some exogenous probability, each consumer either observes two prices or observes one price. Firms also randomize between charging low prices and charging high. 


\section{THE MODEL}

In this section we present the model.

We develop a model that meets two criteria: (i) it captures the main effects of the information characteristics of search platforms, and (ii) it generates predictions that can be tested experimentally. The latter aspect implies a stylized formalism that abstracts from non-testable behavior. ${ }^{7}$ Various footnote extensions complement the model's conciseness.

\subsection{The Setting}

Consider a market for a homogeneous search good that opens for one period. There are: (i) one price-comparison search platform, "search platform" for short, (ii) $n \geq 3$ vendors, indexed through subscript $j=1, \ldots, n$, and (iii) many consumers. ${ }^{8}$

The game unfolds as follows. First, vendors choose prices. Second, the search platform collects and disseminates price information. Third, consumers make their purchases.

\subsection{Consumers}

There is a unit mass of consumers. Consumers are risk neutral. Each consumer has a unit demand, and a reservation price of 1 . There are 2 types of consumers, differing only with respect to whether they use the search platform. Non-Searchers, a proportion $\lambda$ on $(0,1)$, do not use the search platform, perhaps because they are unaware of its existence, or perhaps because of the high opportunity cost of their time. ${ }^{9}$ The other consumers, Searchers, use the search platform. ${ }^{10}$

Consumers do not know the prices charged by individual vendors. Searchers use the search platform to learn the prices of vendors. If the lowest price sampled by the search platform is no higher than 1, searchers accept the offer and buy; in case of a tie they distribute themselves randomly among vendors; otherwise they reject the offer and exit the market. Non-searchers distribute themselves evenly across vendors, i.e., each vendor has a share of non-searchers of $\frac{1}{n}$. If offered a price no higher than 1, non-searchers accept the offer and buy; otherwise they reject the offer and exit the market.

7. In a richer model, the effects of the search platform's characteristics would be intertwined with other effects, making it hard, if not impossible, to test them experimentally.

8. The case where several search platforms compete is certainly of interest. We start with the case of a monopolist search platform because it is easier and leave the case of competing search platforms for further research.

9. To use search platforms consumers incur some cost. In the Blue Book case they have to buy it and spend some time reading it. In the case of online search platforms they might have to download software and spend time finding and comparing alternatives.

10. Consumer types can be endogeneized. To use the search platform one must pay $\alpha$ and spend time reading and processing the information, whose disutility is $d$. Denote by $\varepsilon$ the expected price, by $\mu$ the expected minimum price and let $\Delta:=\varepsilon-\mu$. The utility of using the search platform and buying is: $1-\mu-\alpha-d$; the utility of not using the search platform and buying is $1-\varepsilon$; otherwise the utility is 0 . A consumers uses the search platform if: $d \leq \Delta-\alpha$. Let there be two types of consumers. A proportion $\lambda$ has $d=1$ and a proportion $1-\lambda$ has $d=0$. In equilibrium, $0 \leq \Delta-\alpha \leq 1$ : consumers with $d=0$, i.e., searchers, use the search platform, whereas consumers with $d=1$, i.e., non-searchers, do not. It is straightforward to generalize to any finite number of types. 


\subsection{Vendors}

Vendors are identical and risk neutral. Marginal costs are constant and equal to zero.

Vendors cannot distinguish between searchers and non-searchers. ${ }^{11}$ Denote by $\Pi_{j}(p)$, the expected profit of vendor $j$ when it charges price $p$ on $\mathbb{R}_{0}^{+}$. A vendor's strategy is a cumulative distribution function over prices, $F_{j}(\cdot)$. Denote the lowest and highest prices on its support by $\underline{p}_{j}$ and $\bar{p}_{j} .{ }^{12}$ A vendor's payoff is its expected profit.

\subsection{Price-Comparison Search Platform}

The Price-Comparison Search Platform, for a given sample of vendors, collects their names, addresses and prices and stores it in its database, i.e., in its Index. This information is available to all of those that access the search platform. The search platform has only an informative role and is not used to conduct transactions.

Denote by $k$, the number of vendors the search platform indexes. We will refer to $k$ as the Size of the Index. The search platform may be of one of the following three types:

(i). Complete Coverage: The search platform has Complete Coverage if it indexes all vendors present in the market: $k=n$. Otherwise it has Incomplete Coverage: $1 \leq k<n$.

(ii). Unselective Incomplete Coverage: A search platform with incomplete coverage has a Unselective Sample if, for $1<k<n$, it indexes each of the $n$ vendors with the same probability: $\left(\begin{array}{l}n-1 \\ k-1\end{array}\right) /\left(\begin{array}{l}n \\ k\end{array}\right)=\frac{k}{n}$. If the search platform has incomplete coverage and an unselective sample, we say that it has Unselective Incomplete Coverage.

(iii). Selective Incomplete Coverage: A search platform with incomplete coverage has a Selective Sample if, for $1<k<n$, it indexes vendors $j=1, \ldots, k$, and does not index vendors $j=k+1, \ldots, n$. If the search platform has incomplete coverage and a selective sample, we say that it has Selective Incomplete Coverage. ${ }^{13}$

Complete Coverage is a benchmark case, where the search platform has comprehensive information. Unselective and Selective Incomplete Coverage are two polar cases on how the sample is chosen.

11. In our context it is unclear how consumers could be distinguished. Consider Kelley's blue book. First, searchers have no incentive to signal their type. They are perfectly informed and will buy from the cheapest car dealer anyway. Second, non-searchers have no way of credibly mimicking searchers. If they were informed they would simply go to the cheapest car dealer. Third, vendors have no incentive in using a screening strategy like: post a high price and if confronted, through haggling, with a searcher lower the price. If a vendor posts a high price it will not be visited by searchers. The Internet increased the ability to discriminate consumers, particularly when the search platform is used to conduct transactions, which is not our case. However, this enhanced ability is mitigated by the consumers' aversion to blatant forms of discrimination.

12. As it is well known this game has no equilibrium in pure strategies (Varian, 1980).

13. For this parametrization, knowing the probability with which vendors are indexed, implies knowing the identity of the indexed vendors. It is possible to introduce selectiveness, such that knowing the probability with which vendors are indexed does not imply knowing the identity of the indexed vendors. E.g., all vendors can be indexed with a non-degenerate probability, which is higher for some vendors than for others. Our parametrization has the advantage of yielding a closed form solution. 
Consumers and vendors know the type of the search platform. In particular, under Unselective Incomplete Coverage, vendors know the probability with which they are indexed, but do not observe the identity of the indexed vendors, before choosing prices. Under Selective Incomplete Coverage, vendors know the identity of the indexed vendors before choosing prices. In the cases of Complete Coverage and Unselective Incomplete Coverage, vendors are identical. In the case of Selective Incomplete Coverage, vendors are asymmetric.

Denote by $\tau$ the type of the search platform, and let ' $c$ ', mean Complete Coverage, ' $u$ ' mean Unselective Incomplete Coverage, and ' $s$ ' mean Selective Incomplete Coverage, i.e., $\tau$ belongs to $\{c, u, s\}$. We will use superscripts ' $c$ ', ' $u$ ', ' $s$ ', to denote variables or values associated with the cases where the search platform has that type. ${ }^{14}$

\section{CHARACTERIZATION OF EQUILIBRIUM}

The equilibrium concept is Nash equilibrium in mixed strategies, where vendors choose price distributions.

Denote by $\phi_{j}^{\tau}$, the probability of firm $j$ being indexed, given that the search platform is of type $\tau$ :

$$
\phi_{j}^{\tau}= \begin{cases}\frac{k}{n} & \text { if } \tau=c, u \\ 1 & \text { if } \tau=s \text { and } j=1, \ldots, k \\ 0 & \text { if } \tau=s \text { and } j=k+1, \ldots, n .\end{cases}
$$

Ignoring ties, ${ }^{15}$ the expected profit of a vendor that charges $p \leq 1$ is: ${ }^{16}$

$$
\Pi_{j}(p)=p \frac{\lambda}{n}+p(1-\lambda) \phi_{j}^{\tau}[1-F(p)]^{k-1} .
$$

Denote by $l_{j}^{\tau}$ the lowest price vendor $j$ is willing to charge to sell to both types of consumers when the search platform has type $\tau$, i.e., $l_{j}^{\tau}\left[\frac{\lambda}{n}+(1-\lambda) \phi_{j}^{\tau}\right]-\frac{\lambda}{n} \equiv 0$.

In equilibrium: ${ }^{17}$

$$
p \frac{\lambda}{n}+p(1-\lambda) \phi_{j}^{\tau}\left[1-F_{j}^{\tau}(p)\right]^{k-1}=\frac{\lambda}{n} .
$$

Denote by $\delta(p)$, the degenerate distribution with unit mass on $p .{ }^{18}$ The next proposition characterizes the equilibrium for the model.

14. To endogeneize $(\tau, k, \alpha)$ consider the following four stage game. Stages 2, 3 and 4 unfold as previously described. In stage 1 the search platform chooses $(\tau, k, \alpha)$. From footnote 10, non-searchers do not use the search platform for any $0 \leq \alpha$; searchers use the search platform if, $0 \leq \alpha \leq \Delta^{\tau}$. Hence: $\alpha^{*}=\Delta^{\tau}$. From Proposition $1, \Delta^{\tau}$ is a function of $k$ : $\Delta^{\tau}(k)$. Denote by $C^{\tau}(k)$ the cost of indexing $k$ vendors of a type $\tau$ search platform. The profit of indexing $k$ vendors is: $(1-\lambda) \Delta^{\tau}(k)-C^{\tau}(k)$. Given enough concavity there is unique profit maximizing $k^{*}$. Given $\left(\alpha^{*}, k^{*}\right)$, the search platform can compute the maximum profit for $\tau=u, s$ and choose the most profitable.

15. Lemma 1(ii) in the appendix shows that $F_{j}^{\tau}(\cdot)$ is continuous.

16. Vendor $j$ that charges price $p \leq 1$ sells to searchers: (i) if it belongs to the set of vendors indexed by search platform, which occurs with probability $\phi_{j}^{\tau}$, and (ii) if it has the lowest price among the indexed vendors, which occurs with probability $[1-F(p)]^{k-1}$. Thus, vendor $j$ 's expected share of searchers is: $(1-\lambda) \phi_{j}^{\tau}[1-F(p)]^{k-1}$.

17. From Lemma 1(iv) in the appendix.

18. Function $\delta(\cdot)$ is the Heavside function, i.e., the CDF of the Dirac delta function. 
Proposition 1. (i) for $\tau=c, u$ and $j=1, \ldots, n$, and for $\tau=s$ and $j=1, \ldots, k$ :

$$
F_{j}^{\tau}(p ; n, k)= \begin{cases}0 & \Leftarrow p<l_{j}^{\tau} \\ 1-\left[\left(\frac{1}{n \phi_{j}^{\tau}}\right)\left(\frac{\lambda}{1-\lambda}\right)\left(\frac{1-p}{p}\right)\right]^{\frac{1}{k-1}} & \Leftarrow l_{j}^{\tau} \leq p<1 \\ 1 & \Leftarrow 1 \leq p,\end{cases}
$$

with

$$
l_{j}^{\tau}(n)=\frac{\lambda}{\lambda+(1-\lambda) n \phi_{j}^{\tau}}
$$

(ii) for $\tau=s$ and $j=k+1, \ldots, n, F_{j}^{s}(p ; n, k)=\delta(1)$.

Under Selective Incomplete Coverage, vendors $j=k+1, \ldots, n$, are not indexed for sure, and therefore have no access to searchers. Since these vendors can only sell to non-searchers, which are captive consumers, they charge the reservation price. Vendors $j=1, \ldots, k$, under Selective Incomplete Coverage, and all vendors in the cases of Complete Coverage and Unselective Incomplete Coverage, are indexed with positive probability. Hence, they face the trade-off of charging a high price and selling only to non-searchers, or charging a low price to try to sell also to searchers, which leads them to randomize over prices.

\section{ANALYSIS}

In this section, we analyze the model for the 3 types of search platforms.

\subsection{Complete Coverage}

In the case of Complete Coverage the model is similar to Varian (1980). ${ }^{19}$

Rewrite (2) as:

$$
\underbrace{p(1-\lambda)\left[1-F^{c}(p)\right]^{n-1}}_{\text {Marginal Benefit }}=\underbrace{\frac{\lambda}{n}(1-p)}_{\text {Opportunity Cost }} .
$$

If a vendor charges a price $p$ lower than the consumers' reservation price, 1 , it has the lowest price in the market with probability $\left[1-F^{c}(p)\right]^{n-1}$, sells to $(1-\lambda)$ searchers, and earns an additional expected profit of $p(1-\lambda)\left[1-F^{c}(p)\right]^{n-1}$ : the Volume of Sales effect. However, it loses $(1-p)$ per non-searcher, and a total of $(1-p) \frac{\lambda}{n}$ : the per Consumer Profit effect. The volume of sales effect is the marginal benefit of charging a price lower than the consumers' reservation price, and the per consumer profit effect is the marginal cost.

Denote by $\varepsilon$, the expected price, i.e., the expected price paid by non-searchers. And denote by $\mu$, the expected minimum price, i.e., the expected price paid by searchers.

The next Remark collects two useful observations.

Remark 1. (i) $\lambda \varepsilon^{c}+(1-\lambda) \mu^{c}=\lambda$; (ii) $\mu^{c}<\varepsilon^{c}$.

19. See also Rosenthal (1980) and Stahl (1989). 
The first part of Remark 1 says that the average price paid in the market, $\lambda \varepsilon^{c}+(1-\lambda) \mu^{c}$, equals the proportion of non-searchers, $\lambda .^{20}$ This has two implications. First, only shifts in the proportion of non-searchers change the average price paid in the market. Second, shifts in any other parameter, such as the number of vendors, $n$, induce the expected prices paid by searchers and non-searchers to move in opposite directions. A conflict of interests between types of consumers is an important consequence of this model.

The second part of Remark 1, says that the expected price paid by searchers, $\mu^{c}=l^{c}+$ $\int_{l^{c}}^{1}\left(1-F^{c}\right)^{n} d p$, is lower than the expected price paid by non-searchers, $\varepsilon^{c}=l^{c}+\int_{l^{c}}^{1}\left(1-F^{c}\right) d p$. The search platform allows searchers to compare the prices of all vendors in its index, and choose the cheapest vendor. This induces competition among vendors and puts downward pressure on prices, which benefits consumers using the search platform.

\subsection{Unselective Incomplete Coverage}

In this subsection, we analyze the case of Unselective Incomplete Coverage, and compare it with the case of Complete Coverage. We show that Unselective Incomplete Coverage compared with Complete Coverage, increases the expected price paid by searchers, and decreases the expected price paid by non-searchers.

The price distribution for the case in which the market consists of $n$ vendors, and the price-comparison search platform has an unselective index of size $k \leq n$, is identical to the price distribution for the case in which the search platform has Complete Coverage, $k=n$, and the market consists of $k$ vendors: $F^{u}(\cdot ; n, k)=F^{c}(\cdot ; k)$. For further reference, we present this observation in the next corollary.

Corollary 1. $F^{u}(\cdot ; n, k)=F^{c}(\cdot ; k)$.

The next proposition analyzes the impact of changes in the size of the index, $k$, and the number of vendors, $n$.

Proposition 2. (i) $l^{u}(k)<l^{u}(k-1)$; (ii) $\mu^{u}(n, k)<\mu^{u}(n, k-1)$ and $\varepsilon^{u}(n, k)>\varepsilon^{u}(n, k-$ 1); (iii) $F^{u}(\cdot ; n, k)=F^{u}(\cdot ; n+1, k)$.

Rewrite (2) as:

$$
p(1-\lambda)\left(\frac{k}{n}\right)\left[1-F^{u}(p)\right]^{k-1}=\frac{\lambda}{n}(1-p) .
$$

From (4), an unselective decrease in the size of the index has two impacts. First, for indexed vendors, the decrease in the size of the index reduces the number of rivals with which a vendor has to compete to sell to searchers from $k-1$ to $k-2$. This increases the probability that an indexed vendor will have the lowest price, $\left(1-F^{u}\right)^{k-1}$, which increases the Volume of Sales effect. The first impact leads vendors to shift probability mass from higher to lower prices. As a consequence, the price distribution shifts to the left, as shown in Figure 1. Second, the

20. Actually, it equals the proportion of non-searchers times the reservation price: $\lambda \cdot 1$. Also, since marginal cost is 0 , and demand is inelastic and unitary, the average price paid in the market equals the average market profits. 


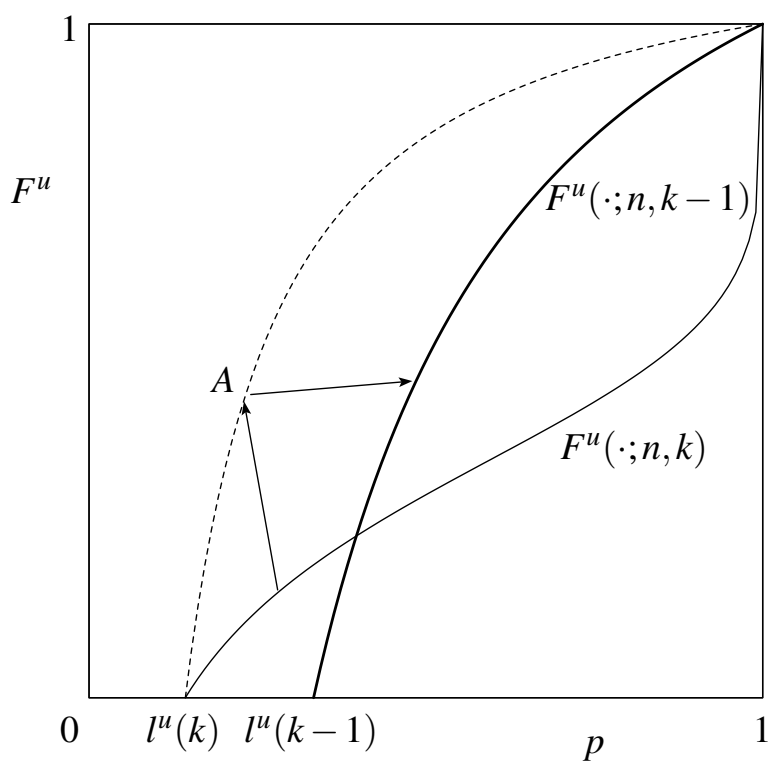

FIGURE 1

Unselective Incomplete Coverage: A decrease in the size of the index: the first impact causes the distribution to shift from $F^{c}(\cdot ; n)$ to $A$, and the second impact causes the distribution to shift from $A$ to $F^{u}(\cdot ; n, k)$.

decrease in the size of the index reduces the probability that a given vendor is indexed from $\frac{k}{n}$ to $\frac{k-1}{n}$, which reduces the Volume of Sales effect. The second impact leads vendors to raise the lower bound of the support, and to shift probability mass from lower to higher prices. As a consequence, the price distribution rotates, as shown in Figure 1. The total impact of an unselective decrease in the size of the index is to cause the price distribution to rotate counter clock-wise. $^{21}$

The increase in the lower bound of the support, $l^{u}(k)<l^{u}(k-1)$, raises the expected price paid by searchers, $\mu^{u}(n, k)<\mu^{u}(n, k-1)$. However, from Remark 1(i), the average price paid in the market remains constant and equal to $\lambda$. This implies that the expected price by nonsearchers decreases, $\varepsilon^{u}(n, k)>\varepsilon^{u}(n, k-1){ }^{22}$ Recall that vendors now charge lower prices with a higher probability. Searchers and non-searchers have conflicting interests with respect to Unselective Incomplete Coverage, as compared with Complete Coverage. Searchers prefer a large to a small unselective index, and non-searchers prefer a small to a large unselective index.

Under Unselective Incomplete Coverage, the equilibrium price distribution does not depend on the number of vendors in the market, $F^{u}(\cdot ; n, k)=F^{u}(\cdot ; n+1, k)$. This result is unexpected. The probability with which a vendor is indexed, $k / n$, depends on the number of vendors. Besides, each vendor's share of non-searchers, $\lambda / n$, also depends on the number of vendors. But from (4), $n$ cancels out, and only the number of vendors whose price searchers compare matters. Rosenthal (1980) assumed that the increase in the number of vendors is accompanied by a proportional increase in the measure of non-searchers. In his setting, an increase in the number of vendors induces first-order stochastically dominating shifts in the price distribution, and therefore higher prices for both types of consumers. The contrast between his and this result

21. See Guimarães (1996) for a related discussion.

22. See Morgan et al. (2006) for a related discussion. 
illustrates another important property of this model. In this sort of markets, the impact of entry depends critically on the way entry occurs.

The next corollary compares the cases of Complete Coverage and Unselective Incomplete Coverage.

Corollary 2. (i) $l^{c}(n)<l^{u}(k)$; (ii) $\mu^{c}(n)<\mu^{u}(n, k)$ and $\varepsilon^{c}(n)>\varepsilon^{u}(n, k)$.

Given that $F^{u}(\cdot ; n, k)=F^{c}(\cdot ; k)$, comparing the price distributions under Unselective Incomplete Coverage, $F^{u}(\cdot ; n, k)$, and under Complete Coverage, $F^{c}(\cdot ; n)$, is equivalent to comparing $F^{u}(\cdot ; n, k)$ and $F^{u}(\cdot ; n, n)$, i.e., is equivalent to analyzing the impact of an increase in the size of the index, under Unselective Incomplete Coverage. Thus, compared with Complete Coverage, Unselective Incomplete Coverage causes the price-comparison to rotate counter-clockwise, which increases the expected price paid by searchers, $\mu^{c}(n)<\mu^{u}(n, k)$, and decreases the expected price paid by non-searchers, $\varepsilon^{c}(n)>\varepsilon^{u}(n, k)$.

\subsection{Selective Incomplete Coverage}

In this subsection, we analyze the case of Selective Incomplete Coverage, and compare it with the other two cases. We show that Selective Incomplete Coverage, compared with both Unselective Incomplete Coverage and with Complete Coverage, decreases the expected price paid by searchers and non-searchers that buy from indexed vendors, and increases the expected price paid by non-searchers that buy from non-indexed vendors.

The next proposition analyzes the impact of changes in the size of the index, $k$, and the number of vendors, $n$.

Proposition 3. (i) For $j=1, \ldots, k, F_{j}^{s}(\cdot ; n, k) \leq F_{j}^{s}(\cdot ; n, k-1)$; (ii) $\mu_{j}^{s}(n, k-1)<\mu_{j}^{s}(n, k)$ and $\varepsilon_{j}^{s}(n, k-1) \leq \varepsilon_{j}^{s}(n, k)$; (iii) For $j=1, \ldots, k, F_{j}^{s}(\cdot ; n+1, k) \geq F_{j}^{s}(\cdot ; n, k)$; (iv) $\mu_{j}^{s}(n+1, k)<$ $\mu_{j}^{s}(n, k)$ and $\varepsilon_{j}^{s}(n+1, k) \leq \varepsilon_{j}^{s}(n, k)$, with strict inequality for $j=1, \ldots, k$.

Rewrite (2) as

$$
p(1-\lambda)\left[1-F_{j}^{s}(p)\right]^{k-1}=\frac{\lambda}{n}(1-p) .
$$

From (5), a decrease in the size of a selective index, $k$, increases the probability that an indexed vendor has the lowest price, $\left(1-F_{j}^{s}\right)^{k-1}$, which increases the Volume of Sales effect. This leads indexed vendors to shift probability mass from higher to lower prices. As a consequence, the distribution shifts in the first-order stochastically dominated sense, $F_{j}^{s}(p ; n, k) \leq$ $F_{j}^{s}(p ; n, k-1)$, as shown in Figure 2a. This decreases the expected price paid by searchers, $\mu_{j}^{s}(n, k-1)<\mu_{j}^{s}(n, k)$, and by non-searchers that buy from an indexed vendor, $\varepsilon_{j}^{s}(n, k-1)<$ $\varepsilon_{j}^{s}(n, k), j=1, \ldots, k$, and leaves unchanged the expected price paid by non-searchers that buy from a non-indexed vendor, $\varepsilon_{j}^{s}(n, k-1)=\varepsilon_{j}^{s}(n, k), j=k+1, \ldots, n$.

From (5), an increase in the number of vendors in the market, $n$, leaving fixed the size of a selective index, $k$, reduces the per Consumer Profit effect. This leads indexed vendors to reduce the lower bound of the support, and to shift probability mass from higher to lower prices. As a consequence, the distribution shifts in the first-order stochastically dominated sense, $F_{j}^{s}(p ; n+$ $1, k) \geq F_{j}^{s}(p ; n, k)$, as shown in Figure $2 \mathrm{~b}$. This decreases the expected price paid by searchers, 


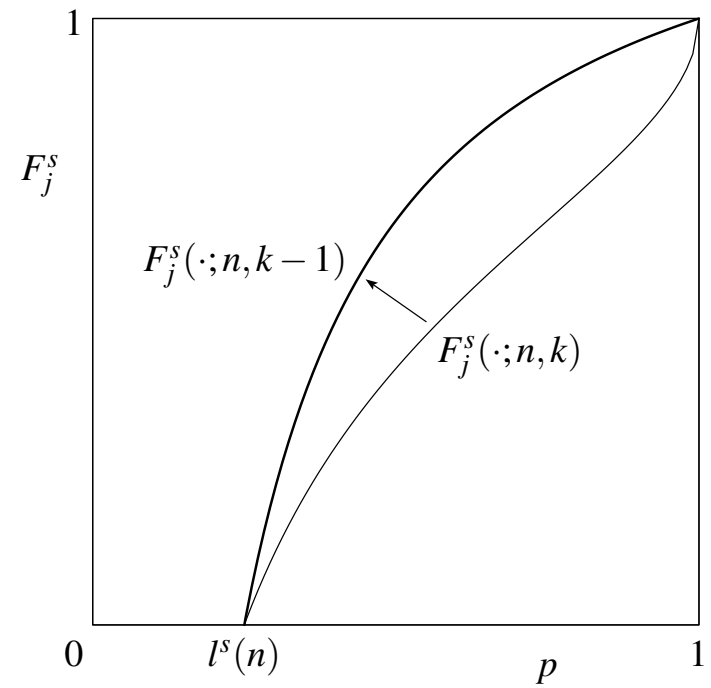

(a) A Decrease in the Size of the Index

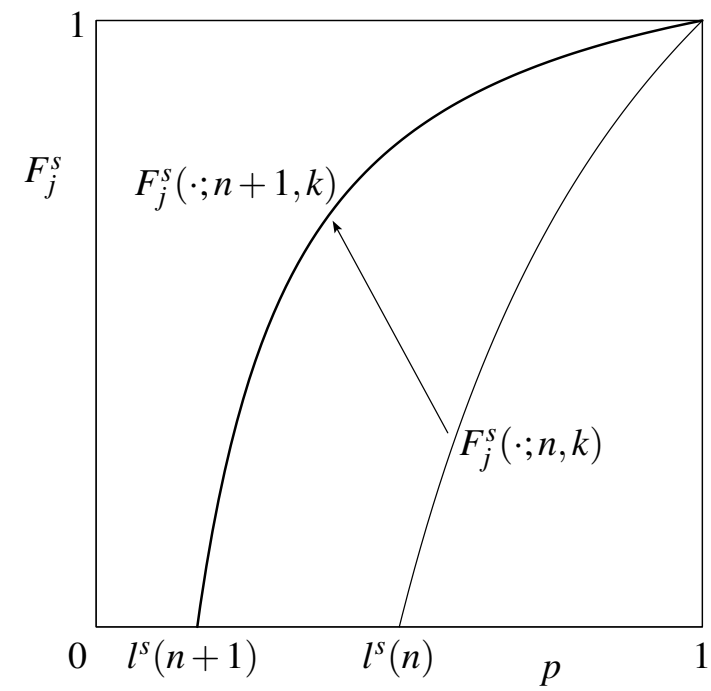

(b) An Increase in the Number of Firms

FIGURE 2

Selective Incomplete Coverage: (a) A decrease in the size of the index. For $j=1, \ldots, k$ distributions $F_{j}^{s}(\cdot ; n, k-1)$ are first-order stochastically dominated by distributions $F_{j}^{s}(\cdot ; n, k)$. (b) An increase in the number of firms. For $j=1, \ldots, k$ distributions $F_{j}^{s}(\cdot ; n+1, k)$ are first-order stochastically dominated by distributions $F_{j}^{s}(\cdot ; n, k)$.

$\mu_{j}^{s}(n+1, k)<\mu_{j}^{s}(n, k)$, and by non-searchers that buy from an indexed vendor, $\varepsilon_{j}^{s}(n+1, k)<$ $\varepsilon_{j}^{s}(n, k), j=1, \ldots, k$, and leaves unchanged the expected price paid by non-searchers that buy from a non-indexed vendor, $\varepsilon_{j}^{s}(n+1, k)=\varepsilon_{j}^{s}(n, k), j=k+1, \ldots, n .^{23}$

The next corollary compares the case of Selective Incomplete Coverage, with the two previous cases.

Corollary 3. (i) $l^{s}(n)=l^{c}(n)$; (ii) For $j=1, \ldots, k, F_{j}^{s}(\cdot ; n, k) \geq \max \left\{F^{c}(\cdot ; n), F^{u}(\cdot ; n, k)\right\}$, andfor $j=k+1, \ldots, n, F_{j}^{s}(\cdot ; n, k) \leq \min \left\{F^{c}(\cdot ; n), F^{u}(\cdot ; n, k)\right\} ;$ (iii) $\mu_{j}^{s}(n, k)<\min \left\{\mu^{c}(n), \mu^{u}(n, k)\right\}$; (iv) For $j=1, \ldots, k, \varepsilon_{j}^{s}(n, k)<\min \left\{\varepsilon^{c}(n), \varepsilon^{u}(n, k)\right\}$, and for $j=k+1, \ldots, n, \varepsilon_{j}^{s}(n, k)>\max \left\{\varepsilon^{c}(n)\right.$, $\left.\varepsilon^{u}(n, k)\right\}$.

For indexed vendors, Selective Incomplete Coverage involves only the positive impact of the Volume of Sales effect, which leads vendors to shift probability mass from higher to lower prices. Thus, the price distribution of indexed vendors, $F_{j}^{s}(\cdot ; n, k)$, is first-order stochastically dominated by price distribution under Complete Coverage, $F^{c}(\cdot ; n)$, and by the price distribution under Unselective Incomplete Coverage $F^{u}(\cdot ; n, k)$, as shown in Figure 3. Searchers buy from the cheapest indexed vendor. Thus, the expected price paid by searchers is smaller under Selective Incomplete Coverage, than under either Complete Coverage, or Unselective Incomplete Coverage. For non-searchers that buy from an indexed vendor, the expected price is also smaller. For non-searchers that buy from a non-indexed vendor, the expected price paid is higher.

23. As $n \rightarrow \infty, l^{s} \rightarrow 0$, and $F_{j}^{s}$ converges weakly to $\delta(1), j=1, \ldots, k$. 


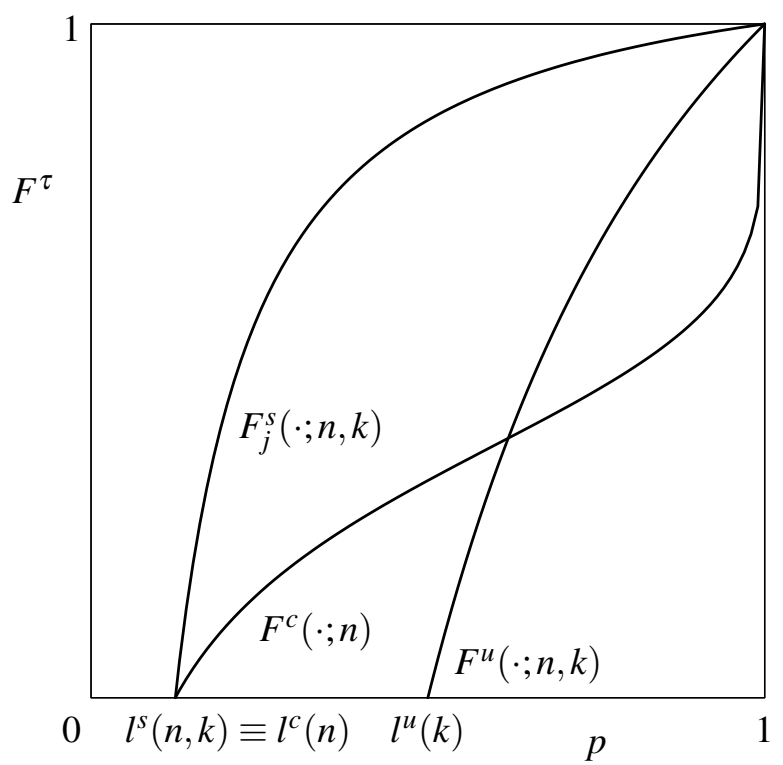

FIGURE 3

Comparison among the three types of coverage. For $j=1, \ldots, k$ distributions $F_{j}^{s}(\cdot ; n, k)$ are first-order stochastically dominated by distributions $F^{c}(\cdot ; n)$ and $F^{u}(\cdot ; n, k)$.

\section{EXPERIMENTAL EVIDENCE}

We experimentally test the predictions of the theoretical model in the presence of interacting human agents. Especially, we are interested in the robustness of predictions obtained under the assumptions of the partial equilibrium search model analysed in the preceding pages in a more realistic setting in which agents, rather than optimizing under unlimited calculus ability, they learn through feedback from past actions. We undertake this task here, exposing a sample of participants, to a context closely replicating the conditions of the theoretical model in a set up which allows us to replicate the aforementioned cases of complete, incomplete/unselective and selective coverage of vendor prices in an oligopolistic market. In this section, we describe the design and report the results of the laboratory experiment.

\subsection{Experimental Design}

The experiment was conducted at the Laboratori d'Economia Experimental (LEE), of the Universitat Jaume I, Castellón, Spain. A population of 144 subjects was recruited in advance among the students of Business Administration, and other business-related courses taught at this university.

Table 1 reports the design parameters of each treatment and the moments of the distributions of average price and minimum price holding under the assumptions of the theoretical model presented in the previous sections. It can be seen that the experiment was run under 8 treatments, each one consisting of a single session with 18 subjects. Although a single session was run per treatment, our hypothesis testing is based on comparisons between groups of sessions. It should be noted that the hypotheses concerning differences between selective and unselective incomplete coverage are tested based on differences across three different treatment pairs (T2-T3, T4-T5 and T6-T8). Similarly, differences between complete and incomplete unselective cov- 
erage are also studied by comparing three different treatment pairs (T1-T2, T4-T5 and T4-T7). The same is true for comparative statics concerning the number of firms on the index and in the industry. Each session consisted of the same setup repeated 50 periods. Each period, depending on the treatment, markets of 3 or 6 subjects were randomly formed. This strangers matching protocol was adopted, in order to maintain the experimental environment as close as possible to the one-shot framework of the theoretical model. Subjects were perfectly informed of the underlying model, and their only decision variable in each period was price. The instructions to the subjects are provided in Appendix B).

Consumer behavior was simulated by the local network server. ${ }^{24}$ There were 1,200 simulated consumers. ${ }^{25}$ For representation and interface reasons, and in order to offer a fine grid for the strategy space, the consumers' reservation price was normalized to 1,000 rather than to 1. Half of the consumers were assumed to be searchers, and the other half were non-searchers, i.e., $\lambda=1 / 2$.

Under Complete Coverage, the search platform's index contained the prices of all subjects, i.e., $k=n=3$ or $k=n=6$, depending on the treatment. Under Incomplete Coverage, the index contained the prices of only a subset of all subjects, i.e., $k=2$ for $n=3$, and $k=2$ or $k=4$ for $n=6$. Under Unselective Incomplete Coverage, subjects were informed whether they where indexed after each period's prices were set. Under Selective Incomplete Coverage, subjects were informed on the composition of the index before prices were set. Both in the case of Unselective or Selective Coverage, after each period's prices were set, subjects were informed on own and rival prices, as well as own quantities sold and profits earned. ${ }^{26}$

In order to make the earnings of each period equally interesting, subjects' monetary rewards were calculated from the cumulative earnings over 10 randomly selected periods. Individual rewards ranged between $15 €$ and $50 €$. This made the experiment worth participating in, and increased subjects' motivation to earn the highest payoff possible.

\subsection{Testable Hypotheses}

Denote by $\varepsilon_{t}$, the expected price in treatment $t$; by $\varepsilon_{t}^{i n}$ the expected price of indexed firms in treatment $t$; by $\varepsilon_{t}^{n i}$ the expected price of non-indexed firms in treatment $t$; and by $\mu_{t}$ the expected minimum price in treatment $t$, where $t=1, \ldots, 8$.

Regarding the most well known result of this framework which has also been explicitly tested by Morgan et al. (2006), we test the basic or consistency hypothesis:

HC: Under Complete Coverage, an increase in the number of vendors: (i) decreases the expected minimum price: $\mu_{4}<\mu_{1}$; (ii) increases the average price: $\varepsilon_{4}>\varepsilon_{1}$.

Regarding Unselective Incomplete Coverage we test:

24. We programmed software using z-Tree (Fischbacher, 2007) in order to organize strategy submission, demand simulation, feedback, and data collection.

25. In order to avoid problems associated with the discreteness of the resulting demands, we use a larger number of consumers than that used by Morgan et al. (2006).

26. Subjects observe their rivals' prices for two reasons. First, for realism. Second, in order to achieve faster convergence to experienced play. 


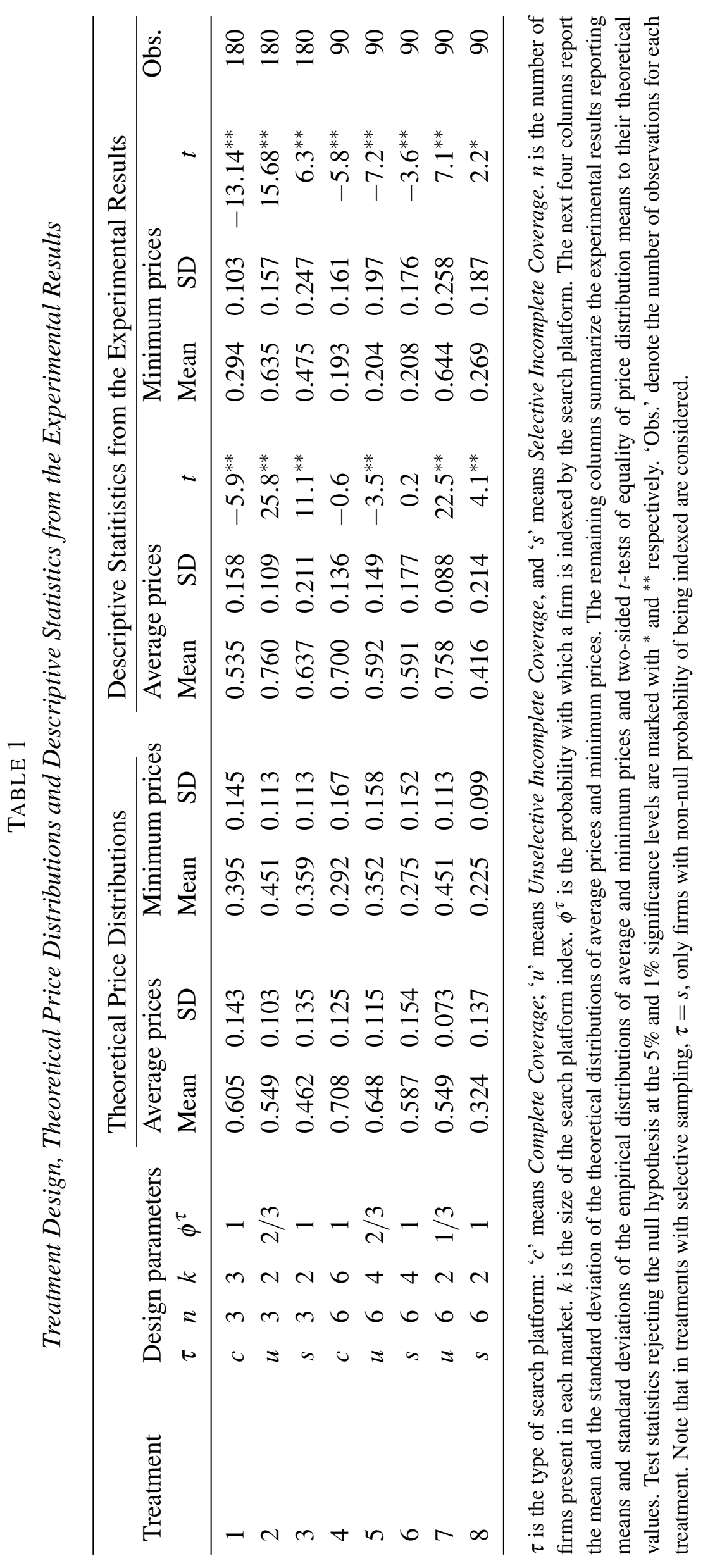


HU1: Under Unselective Incomplete Coverage, a decrease in the size of the index: (i) increases the expected minimum price: $\mu_{4}<\mu_{5}<\mu_{7}$ and $\mu_{1}<\mu_{2}$; (ii) decreases the expected price: $\varepsilon_{4}>\varepsilon_{5}>\varepsilon_{7}$ and $\varepsilon_{1}>\varepsilon_{2}$.

HU2: Under Unselective Incomplete Coverage, the equilibrium price distribution is independent of the number of vendors present in the market: $\mu_{2}=\mu_{7}$ and $\varepsilon_{2}=\varepsilon_{7}$.

Regarding Selective Incomplete Coverage we test:

HB1: Under Selective Incomplete Coverage, a decrease in the size of the index: (i) decreases the expected minimum price: $\mu_{4}>\mu_{6}>\mu_{8}$ and $\mu_{1}>\mu_{3}$; (ii) decreases the expected price of indexed vendors: $\varepsilon_{4}>\varepsilon_{6}^{i n}>\varepsilon_{8}^{i n}$ and $\varepsilon_{1}>\varepsilon_{3}^{i n}$; (iii) leaves unchanged the expected price of non-indexed vendors: $\varepsilon_{6}^{n i}=\varepsilon_{8}^{n i}=1$ and $\varepsilon_{3}^{n i}=1$.

HB2: Under Selective Incomplete Coverage, an increase in the number of vendors in the market: (i) decreases the expected minimum price: $\mu_{3}>\mu_{8}$; (ii) decreases the expected price of indexed vendors: $\varepsilon_{3}^{\text {in }}>\varepsilon_{8}^{\text {in }}$.

We also test the general hypothesis:

HG: (i) The expected minimum price is smaller under Selective Incomplete Coverage, than under Unselective Incomplete Coverage: $\mu_{5}>\mu_{6}$ and $\mu_{7}>\mu_{8}$ and $\mu_{2}>\mu_{3}$; (ii) The expected price of indexed vendors is smaller under Selective Incomplete Coverage, than under Unselective Incomplete Coverage: $\varepsilon_{5}>\varepsilon_{6}^{i n}$, and $\varepsilon_{7}>\varepsilon_{8}^{i n}$, and $\varepsilon_{2}>\varepsilon_{3}^{i n}$.

\subsection{Experimental Results}

Table 1 summarizes the descriptive statistics regarding all treatments. The 20 initial periods are dropped from the data set reported here in order to eliminate learning dynamics and guarantee that observations had reached the necessary stability. ${ }^{27}$ Seven conclusions emerge from the experimental observations.

Observation 1. In quantitative terms, there are systematic differences between the empirical and the theoretical results.

This conclusion can be qualified in at least two alternative ways. First, inspection of the $t$-tests in Table 1 shows that with the exception of the average price for treatments 4 and 6 , all estimated means of average and minimum prices are significantly different from their theoretical values.

27. We focus here on the comparative static results that can be tested by our data. The dynamic properties of individual behavior are studied in detail by García-Gallego et al. (2014), applying specific theoretical results by Janssen and Moraga-González (2004), Benaïm et al. (2009) and Hopkins and Seymour (2002) on the stability of learning dynamics in the framework of search models. 
Second, from Figure 4 we see that, in a strict sense, none of the theoretical distributions completely lies within the confidence regions built. ${ }^{28}$ As we will see bellow, the divergence between predicted and observed behavior, is not incompatible with confirmation of most comparative statics predictions of the theoretical model. As pointed out by Orzen and Sefton (2008), several experimental studies, like Cason and Friedman (2003) and Morgan et al. (2006), have reported that mixed strategy equilibria are successful predictors of the observed comparative statics obtained from laboratory experiments. However, this observation seems to ignore the phenomenon reported here concerning systematic deviations between theoretical and observed price distributions. Recently, Fonseca and Normann (2008) also obtained deviations of observed price distributions from those predicted by the corresponding mixed strategy equilibrium. Earlier, Huck et al. (2004) had also found quantitative differences between theoretical and observed behavior, while their experiments confirmed the predicted comparative statics with respect to the number of firms in the market.

The empirical distributions rotate clock-wise compared to the theoretical ones. In the case of treatments 2 and 3, the empirical distribution "almost" first-order stochastically dominates the theoretical distribution. This rotation indicates the presence of more density on both tails of distributions of observed prices, than the theoretical model would have predicted. On one hand, in some treatments a large number of observations lie below the infimum of the support of the theoretical distributions, $l^{\tau}$, e.g., in treatments 1, 4, 5 and 6. On the other hand, a large number of observations are at the maximum price, $p_{j}=1$. This behavior is specially pronounced in treatments 4, 5, 6, and 7. In line with the way in which the empirical distributions rotate, most of the empirical price distributions have higher standard deviations than the corresponding theoretical ones. See Table 1.

We also found a difference between the expected and the observed behavior of subjects that knew beforehand that they would not be indexed under Selective Incomplete Coverage. In treatments 6 and $8,8 \%$ of the observed prices of these subjects were different from $p_{j}=1$. We suspect that most of these observations were mistakes, as many of these subjects only deviated from the degenerate equilibrium strategy once or twice. But in treatment 3, nearly $30 \%$ of the prices of these subjects were different from $p_{j}=1$, and four of these individuals always choose prices lower than $p_{j}=1$. Clearly, hypothesis HB1 (iii) was not supported by the experimental data.

Observation 2. The data supports the model's predictions regarding changes in the number of firms present in the market.

From Table 2, it follows that: (i) $\mu_{2}=\mu_{7}$ and $\varepsilon_{2}=\varepsilon_{7}$, (ii) $\mu_{3}>\mu_{8}$ and $\varepsilon_{3}^{\text {in }}>\varepsilon_{8}^{\text {in }}$, (iii) $\mu_{1}>\mu_{4}$ and $\varepsilon_{1}<\varepsilon_{4}$. This implies that the data supports hypotheses: HC, HU2, and HB2.

Consider in particular the consistency hypothesis, HC: under Complete Coverage, an increase in the number of vendors increases the average price and decreases the expected minimum price. This conclusion can also be gleaned from the inspection of Figure 5. This nontrivial result was also obtained by Morgan et al. (2006).

28. Intervals surrounding the corresponding empirical cumulative distributions at a maximum distance defined by the $1 \%$ critical values of the Kolmogorov-Smirnov test. 


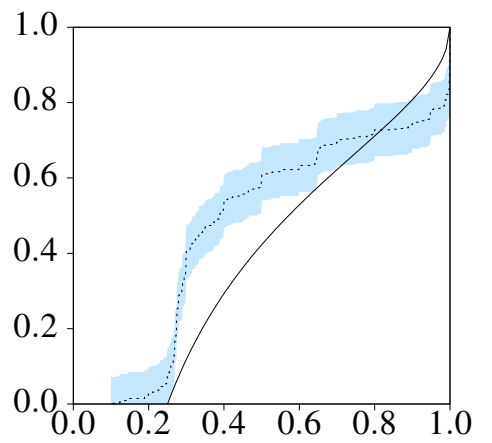

(a) Treatment 1

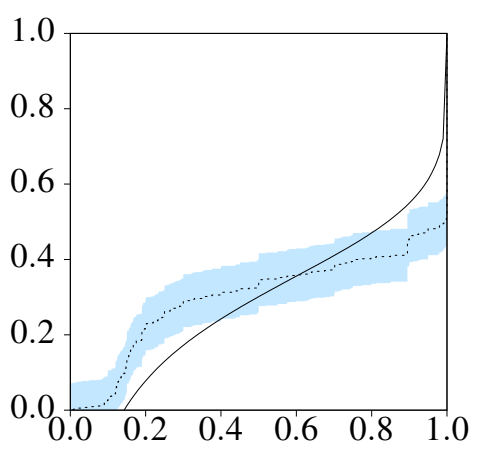

(d) Treatment 4

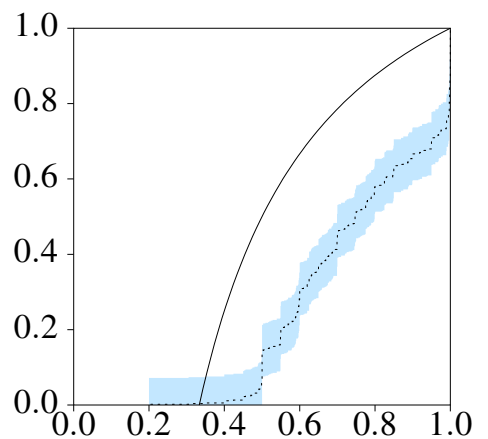

(b) Treatment 2

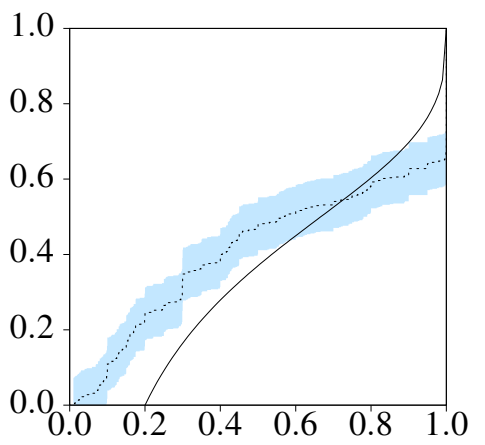

(e) Treatment 5

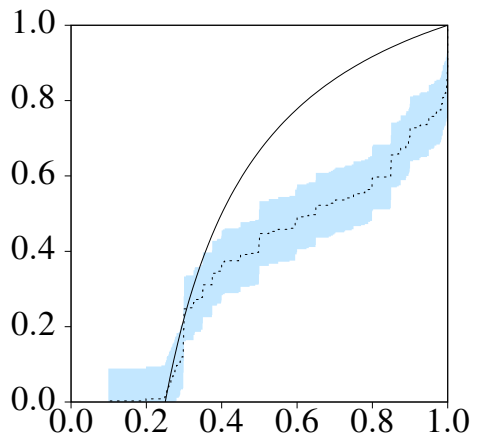

(c) Treatment 3

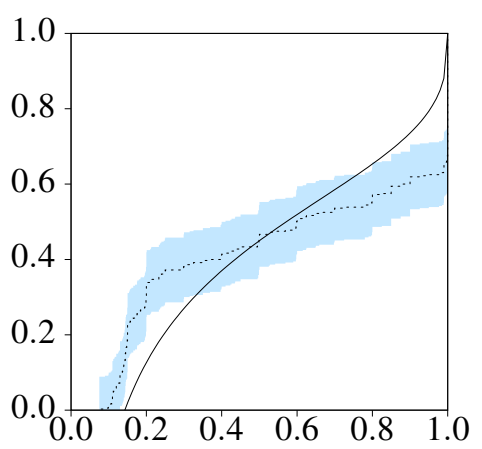

(f) Treatment 6

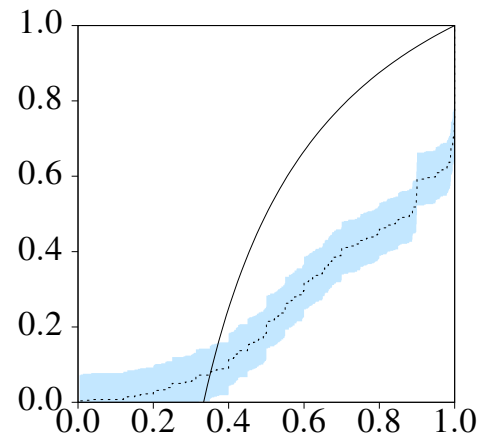

(g) Treatment 7

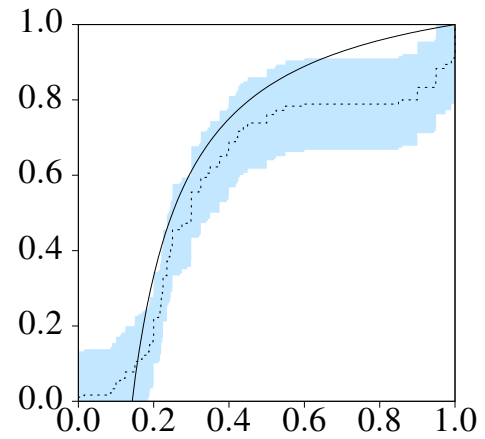

(h) Treatment 8

FIGURE 4

Theoretical (solid lines) and Empirical (dashed line) Price Distributions. Empirical distributions are surrounded with a confidence region built from the $1 \%$ critical values of the Kolmogorov-Smirnov test.

Observation 3. The data supports the model's predictions regarding the comparison between Unselective Incomplete Coverage and Selective Incomplete Coverage.

From Table 2, it follows that: (i) $\mu_{3}<\mu_{2}$ and $\varepsilon_{3}^{i n}<\varepsilon_{2}$, (ii) $\mu_{6}=\mu_{5}$ and $\varepsilon_{6}^{i n}=\varepsilon_{5}$, (iii) $\mu_{8}<\mu_{7}$ and $\varepsilon_{8}^{i n}<\varepsilon_{7}$. The data support hypothesis HG: the average and the average minimum prices are weakly lower under Selective Incomplete Coverage than under Unselective Incomplete Coverage. Both types of consumers, searchers and non-searchers, are better off if the index is selective than if it is unselective. The same conclusion can be gleaned from the inspection of Figure 6 .

Observation 4. The data does not support the model's predictions regarding changes in the size of the index. 
TABLE 2

t-tests of Equality of Means of Average Prices

\begin{tabular}{|c|c|c|c|c|c|c|c|}
\hline & \multicolumn{3}{|c|}{ Average prices } & \multicolumn{3}{|c|}{ Minimum prices } & \multirow[b]{2}{*}{ d. f. } \\
\hline & $H_{0}$ & $H_{1}$ & $t$-test & $H_{0}$ & $H_{1}$ & $t$-test & \\
\hline HC & $\varepsilon_{1}=\varepsilon_{4}$ & $\varepsilon_{1}<\varepsilon_{4}$ & $-8.44^{* *}$ & $\mu_{4}=\mu_{1}$ & $\mu_{4}<\mu_{1}$ & $-6.23^{* *}$ & 268 \\
\hline \multirow[t]{4}{*}{ HU1 } & $\varepsilon_{5}=\varepsilon_{4}$ & $\varepsilon_{5}<\varepsilon_{4}$ & $-5.06^{* *}$ & $\mu_{4}=\mu_{5}$ & $\mu_{4}<\mu_{5}$ & -0.39 & 178 \\
\hline & $\varepsilon_{7}=\varepsilon_{4}$ & $\varepsilon_{7}<\varepsilon_{4}$ & 3.42 & $\mu_{4}=\mu_{7}$ & $\mu_{4}<\mu_{7}$ & $-14.06^{* *}$ & 178 \\
\hline & $\varepsilon_{7}=\varepsilon_{5}$ & $\varepsilon_{7}<\varepsilon_{5}$ & 9.11 & $\mu_{5}=\mu_{7}$ & $\mu_{5}<\mu_{7}$ & $-12.87^{* *}$ & 178 \\
\hline & $\varepsilon_{2}=\varepsilon_{1}$ & $\varepsilon_{2}<\varepsilon_{1}$ & 15.68 & $\mu_{1}=\mu_{2}$ & $\mu_{1}<\mu_{2}$ & $-24.26^{* *}$ & 358 \\
\hline HU2 & $\varepsilon_{2}=\varepsilon_{7}$ & $\varepsilon_{2} \neq \varepsilon_{7}$ & 0.11 & $\mu_{2}=\mu_{7}$ & $\mu_{2} \neq \mu_{7}$ & -0.35 & 268 \\
\hline \multirow[t]{4}{*}{ HB1 } & $\varepsilon_{6}^{i n}=\varepsilon_{4}$ & $\varepsilon_{6}^{i n}<\varepsilon_{4}$ & $-4.64^{* *}$ & $\mu_{6}=\mu_{4}$ & $\mu_{6}<\mu_{4}$ & 0.59 & 178 \\
\hline & $\varepsilon_{8}^{i n}=\varepsilon_{4}$ & $\varepsilon_{8}^{i n}<\varepsilon_{4}$ & $-10.60^{* *}$ & $\mu_{8}=\mu_{4}$ & $\mu_{8}<\mu_{4}$ & 2.91 & 178 \\
\hline & $\varepsilon_{8}^{i n}=\varepsilon_{6}^{i n}$ & $\varepsilon_{8}^{i n}<\varepsilon_{6}^{i n}$ & $-5.96^{* *}$ & $\mu_{8}=\mu_{6}$ & $\mu_{8}<\mu_{6}$ & 2.25 & 178 \\
\hline & $\varepsilon_{3}^{i n}=\varepsilon_{1}$ & $\varepsilon_{3}^{i n}<\varepsilon_{1}$ & 5.19 & $\mu_{3}=\mu_{1}$ & $\mu_{3}<\mu_{1}$ & 9.09 & 358 \\
\hline HB2 & $\varepsilon_{8}^{i n}=\varepsilon_{3}^{i n}$ & $\varepsilon_{8}^{i n}<\varepsilon_{3}^{i n}$ & $-8.07^{* *}$ & $\mu_{8}=\mu_{3}$ & $\mu_{8}<\mu_{3}$ & $-7.00^{* *}$ & 268 \\
\hline \multirow[t]{3}{*}{ HG } & $\varepsilon_{6}^{i n}=\varepsilon_{5}$ & $\varepsilon_{6}^{i n}<\varepsilon_{5}$ & -0.07 & $\mu_{6}=\mu_{5}$ & $\mu_{6}<\mu_{5}$ & 0.15 & 178 \\
\hline & $\varepsilon_{8}^{i n}=\varepsilon_{7}$ & $\varepsilon_{8}^{i n}<\varepsilon_{7}$ & $-14.01^{* *}$ & $\mu_{8}=\mu_{7}$ & $\mu_{8}<\mu_{7}$ & $-11.17^{* *}$ & 178 \\
\hline & $\varepsilon_{3}^{i n}=\varepsilon_{2}$ & $\varepsilon_{3}^{i n}<\varepsilon_{2}$ & $-6.93^{* *}$ & $\mu_{3}=\mu_{2}$ & $\mu_{3}<\mu_{2}$ & $-7.30^{* *}$ & 358 \\
\hline
\end{tabular}

Except for HU2, one-sided $t$-tests with 'd.f' degrees of freedom. The testable implications of section 5.2 correspond to the alternative hypothesis of these tests. For HU2, two-sided $t$-test with 'd.f' degrees of freedom. HU2 correspond to the null hypothesis of this test. Test statistics rejecting the null hypothesis at the 5\% and $1 \%$ significance levels are marked with ${ }^{*}$ and ${ }^{* *}$ respectively.

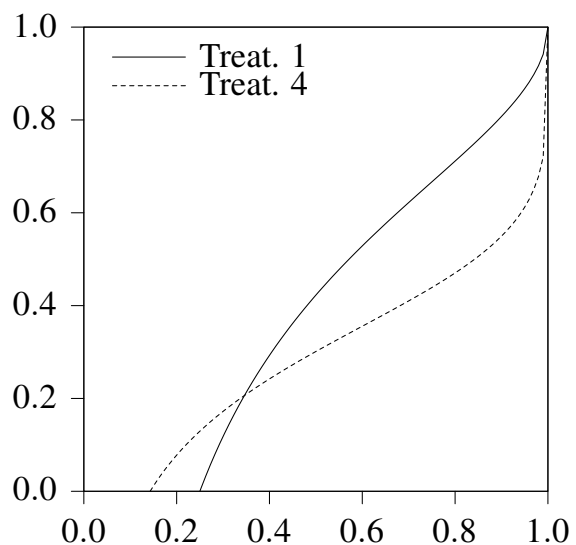

(a) Theoretical distributions

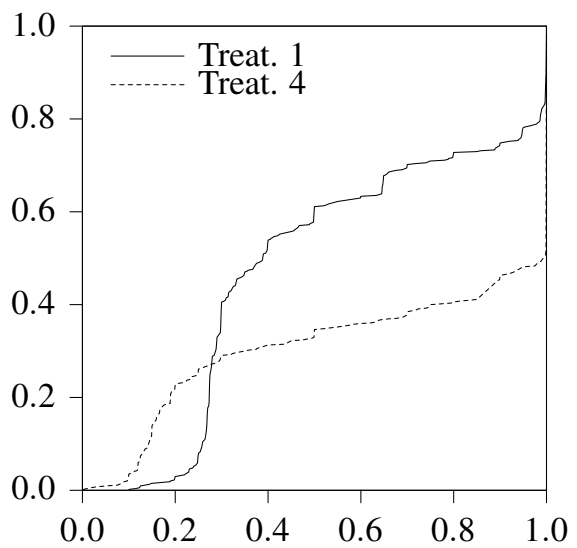

(b) Empirical distributions

FIGURE 5

Comparison of Price Distributions: Complete Coverage. 

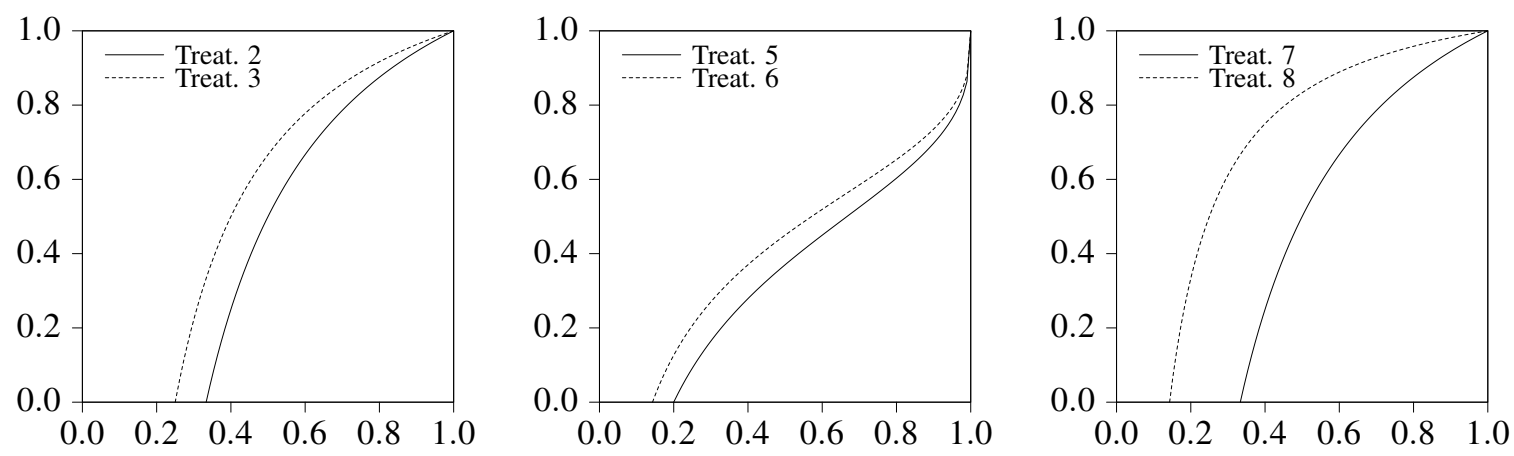

(a) Theoretical distributions
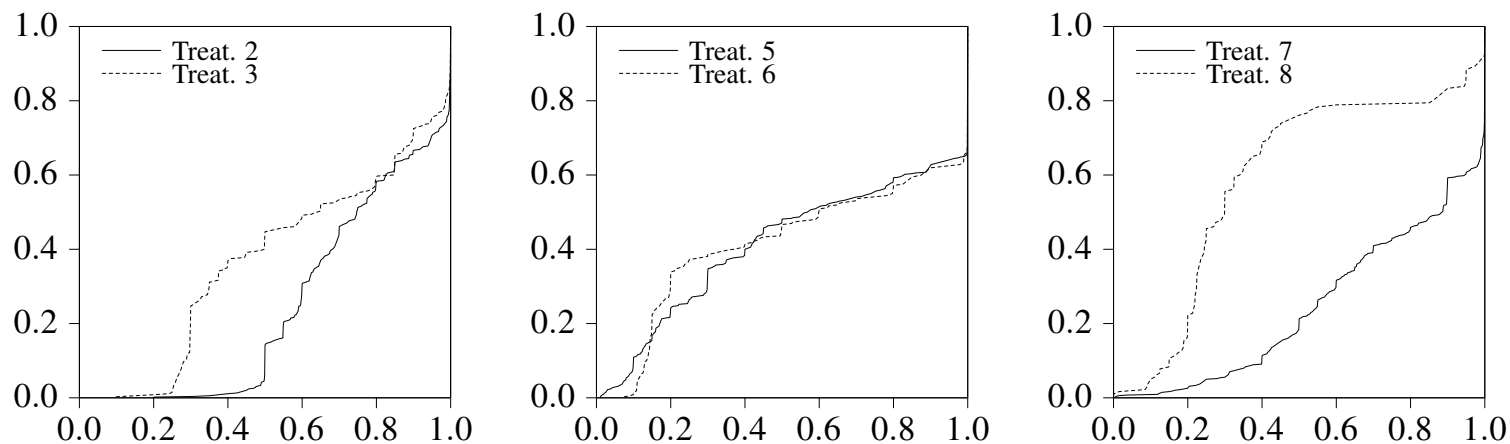

(b) Empirical distributions

FIGURE 6

Comparison of Price Distributions: Incomplete Coverage

From Table 2, it follows that: (i) $\mu_{1}<\mu_{2}$ and $\varepsilon_{1}<\varepsilon_{2}$, (ii) $\mu_{4}<\mu_{7}$ and $\varepsilon_{4}<\varepsilon_{7}$, (iii) $\mu_{5}<\mu_{7}$ and $\varepsilon_{5}<\varepsilon_{7}$, (iv) $\mu_{4}=\mu_{5}$ and $\varepsilon_{4}>\varepsilon_{5}$. This implies that the data does not support hypothesis HU1.

Also from Table 2, it follows that: (i) $\mu_{1}<\mu_{3}$ and $\varepsilon_{1}<\varepsilon_{3}^{i n}$, (ii) $\mu_{4}<\mu_{8}$ and $\varepsilon_{4}>\varepsilon_{8}^{i n}$, (iii) $\mu_{6}<\mu_{8}$ and $\varepsilon_{6}^{i n}>\varepsilon_{8}^{i n}$, (iv) $\mu_{4}=\mu_{6}$ and $\varepsilon_{4}>\varepsilon_{6}^{i n}$. This implies that the data does not support hypothesis HB1, either.

Observation 5. The data does not support the model's predictions regarding the comparison between Complete Coverage and Incomplete Coverage.

With respect to the comparison between Complete Coverage and Unselective Incomplete Coverage, from Table 2, it follows that: (i) $\mu_{4}=\mu_{5}<\mu_{7}$ and $\mu_{1}<\mu_{2}$; (ii) $\varepsilon_{5}<\varepsilon_{4}<\varepsilon_{7}$ and $\varepsilon_{1}<\varepsilon_{2}$. Only the comparison of minimum prices is weakly compatible with the model's predictions. The data fails to support the predicted comparison between Complete Coverage and Unselective Incomplete Coverage, i.e., HU1.

With respect to the comparison between Complete Coverage and Selective Incomplete Coverage, from Table 2, it follows that: (i) $\mu_{4}=\mu_{6}<\mu_{8}$ and $\mu_{1}<\mu_{3}$; (ii) $\varepsilon_{8}^{i n}=\varepsilon_{6}^{\text {in }}<\varepsilon_{4}$ and $\varepsilon_{1}<\varepsilon_{3}^{i n}$. The data fails to support the predicted comparison between Complete Coverage and Selective Incomplete Coverage, i.e., HB1. 
Observation 6. The average minimum price is weakly lower under Complete Coverage than under Selective Incomplete Coverage.

From Table 2 it follows that: (i) $\mu_{1}<\mu_{3}$, (ii) $\mu_{4}=\mu_{6}$, and (iii) $\mu_{4}<\mu_{8}$. Jointly with Observation 3, this imply that searchers are better off under Complete Coverage than under Incomplete Coverage.

Observation 7. Given the type of bias, ratio $k / n$, and Incomplete Coverage, an increase in the number of firms in the market leads to a lower average price, and a lower average minimum price.

From Table 2 it follows that: (i) $\mu_{5}<\mu_{2}$ and $\varepsilon_{5}<\varepsilon_{2}$, and (ii) $\mu_{6}<\mu_{3}$ and $\varepsilon_{6}<\varepsilon_{3}$. This observation agrees with the empirical findings of Baye et al. (2003).

\section{CONCLUSIONS}

In this article, we analyzed the effects on market equilibrium of some information characteristics of price-comparison search platforms, namely: (i) that they only list the prices of some of the vendors in the market, and (ii) that their listings may be more favorable to some vendors than to others. In addition, we analyzed the impact of the number of vendors in the market. We developed a partial equilibrium search model, and tested its predictions in a laboratory experiment specifically designed for that purpose.

The model warns us about possible counter-intuitive effects. For example, an increase in the number of vendors whose prices are listed by the search platform may not imply lower expected prices. The experimental results confirm some of the model's predictions and contradict others.

It is a positive finding of our research that the data confirms one of the basic predictions of our model, as well as of the models of Burdett and Judd (1983) and Varian (1980), concerning the impact of the number of vendors in the market. This positive finding, reinforces the findings by Morgan et al. (2006). ${ }^{29}$ The data also confirms our model's prediction concerning the impact of the search platform's sample not being random. Contrary to these positive findings, the prediction concerning the impact of size of the search platform's sample receive little, if any, support from our data. Future research should investigate the behavioral sources of this failure. For example, it would be interesting to relax the assumption of agents' risk neutrality and generalize the model to the case of alternative risk attitudes. However, the resulting setup would be further complicated by the need of modelling also agents' beliefs on others' risk attitudes. Asymmetric equilibria would emerge, but we would not expect the resulting framework to yield tractable solutions.

The policy issues underlying are important and complex and require much additional analysis. Our results contribute to the policy debate with the following four observations.

First, in these markets there is a fundamental conflict of interests between informed and uninformed consumers. The expected prices paid by these two types of consumers tend to be affected in opposite ways by parameter changes or policy measures. Hence, policy interventions

29. More recent experimental evidence on this is provided by Orzen (2008). 
are delicate exercises that should weight the interests of all parties. In practice, this balancing act might be hard to perform.

Second, consumers should not assume that price-comparison search platforms are independent parties, whose purpose is to provide them useful information. Search platforms are self-interested parties, whose interests may be aligned with those of the vendors, instead of the consumers. ${ }^{30}$ A policy of mandatory disclosure of the commercial affiliations could be useful.

Third, whether or not search platforms are commercially affiliated with vendors, and excluding blatant deceptive information, consumers should be encouraged to use search platforms to both obtain and compare price information. Even when search platforms do not correspond to their ideal type, consumers are better off by using them than by not using them.

Fourth, the impact of the size and type of the search platform's sample of prices, and the number of vendors in the market, should be further investigated. The importance of these markets is growing rapidly, particularly in internet related environments, and the effects involved are delicate.

\section{ACKNOWLEDGEMENTS}

The authors gratefully acknowledge financial support by the NET Institute and the Spanish Ministerio de Economía y Competitividad (project ECO2015-68469-R). P. Pereira acknowledges financial support from Fundação para a Ciência e a Tecnologia and FEDER/COMPETE (grant UID/ECO/04007/2013). This paper benefited from helpful comments by H. Raff, J. Brandts, J. Bröcker, T. Cason, S. Hoernig and M. Sefton.

30. We do not model the choice of the platform type. However, the platform owner will choose the platform type that is most beneficial for his interests, which are not necessarily those of the consumers. 


\section{APPENDIX A. PROOFS}

A Nash equilibrium is a $n$-tuple of cumulative distribution functions over prices, $\left\{F_{1}(\cdot), \ldots, F_{n}(\cdot)\right\}$, such that for some $\Pi_{j}^{\star}$ on $\mathbb{R}_{0}^{+}$, and $j=1, \ldots, n$ : (i) $\Pi_{j}(p)=\Pi_{j}^{\star}$, for all $p$ on the support of $F_{j}(\cdot)$, and (ii) $\Pi_{j}(p) \leq \Pi_{j}^{\star}$, for all $p$.

When vendors are identical we focus on symmetric equilibria, in which case: $F_{j}(\cdot)=F(\cdot)$, $\underline{p}_{j}=\underline{p}, \bar{p}_{j}=\bar{p}$ and $\Pi_{j}^{\star}=\Pi^{\star}$, for all $j$.

Denote by $\hat{p}_{-j}$ the minimum price charged by any indexed vendor other than vendor $j$, and denote by $\hat{m}_{-j}$ the number of indexed vendors that charge $\hat{p}_{-j}$. The profit function of vendor $j$ when it charges price $p_{j}$ is:

$$
\pi_{j}\left(p_{j} ; \tau\right)= \begin{cases}p_{j}\left[\frac{\lambda}{n}+(1-\lambda) \phi_{j}^{\tau}\right] & \text { if } p_{j}<\hat{p}_{-j} \leq 1 \\ p_{j}\left[\frac{\lambda}{n}+\frac{1-\lambda}{\hat{m}_{-j}} \phi_{j}^{\tau}\right] & \text { if } p_{j}=\hat{p}_{-j} \leq 1 \\ p_{j} \frac{\lambda}{n} & \text { if } \hat{p}_{-j}<p_{j} \leq 1 \\ 0 & \text { if } 1<p_{j} .\end{cases}
$$

The next Lemma states some auxiliary results.

Lemma 1. For all $j$ : (i) $l_{j}^{\tau} \leq \underline{p}_{j} \leq \bar{p}_{j} \leq 1$; (ii) $F_{j}^{\tau}$ is continuous on $\left[l_{j}^{\tau}, 1\right]$; (iii) $\bar{p}_{j}=1$; (iv) $\Pi_{j}^{\star}=\frac{\lambda}{n}$; (v) $\underline{p}_{j}=l_{j}^{\tau}$; (vi) $F_{j}^{\tau}$ has a connected support.

Proof of Lemma 1. For $\tau=s$ and $j=k+1, \ldots, n$ the proofs are obvious, so consider: (a) $\tau=s$ and $j=1, \ldots, k$, and (b) $\tau=c, u$.

(i). For any $j$, any price $p_{j}<l_{j}^{\tau}$ or $p_{j}>1$ is strictly dominated by $p_{j}=1$;

(ii). Suppose not, i.e., suppose that $F_{j}^{\tau}$ has a mass point at price $p$. Let $\varepsilon>0$ be arbitrarily small and such that no mass point exists at price $p-\varepsilon$. The expected profits of firm $j$ are:

$$
\begin{aligned}
\Pi_{j}(p-\varepsilon)= & (p-\varepsilon) \frac{\lambda}{n}+(p-\varepsilon)(1-\lambda) \phi_{j}^{\tau} \operatorname{Prob}\left[p-\varepsilon<\hat{p}_{-j}\right] \\
& +(p-\varepsilon)(1-\lambda) \phi_{j}^{\tau} \operatorname{Prob}\left[p-\varepsilon \leq p=\hat{p}_{-j}\right]
\end{aligned}
$$

and

$$
\Pi_{j}(p)=p \frac{\lambda}{n}+p(1-\lambda) \phi_{j}^{\tau} \operatorname{Prob}\left[p<\hat{p}_{-j}\right]+p \frac{(1-\lambda) \phi_{j}^{\tau}}{\hat{m}_{-j}} \operatorname{Prob}\left[p=\hat{p}_{-i}^{j}\right]
$$

Subtracting the second expression from the first and taking the limit as $\varepsilon$ approached zero, one obtains

$$
\lim _{\varepsilon \rightarrow 0}\left[\Pi_{j}(p-\varepsilon)-\Pi_{j}(p)\right]=p(1-\lambda) \phi_{j}^{\tau}\left(\frac{\hat{m}_{-j}-1}{\hat{m}_{-j}}\right) \operatorname{Prob}\left[p=\hat{p}_{-j}\right]>0 .
$$

Hence, vendor $j$ would increase profit by shifting mass from $p$ to an $\varepsilon$ neighborhood below $p$. But this implies that it cannot be an equilibrium strategy to maintain a mass point at $p$; 
(iii). Suppose not, i.e., suppose $\bar{p}_{j}<1$. Then

$$
\Pi_{j}\left(\bar{p}_{j}\right)=\bar{p}_{j} \frac{\lambda}{n}+\bar{p}_{j}(1-\lambda) \phi_{j}^{\tau}\left[1-F\left(\bar{p}_{j}\right)\right]^{k-1}=\bar{p}_{j} \frac{\lambda}{n}
$$

since from (ii) there are no mass points at $\bar{p}_{j} \frac{\lambda}{n}$. However, the payoff from setting a price equal to 1 is $\frac{\lambda}{n}>\bar{p}_{j} \frac{\lambda}{n}$;

(iv). Follows from (ii) and (iii);

(v). Parts (ii) and (iv) imply that $\underline{p}_{j} \frac{\lambda}{n}+\underline{p}_{j}(1-\lambda) \phi_{j}^{\tau}=\Pi_{j}\left(\underline{p}_{j}\right)=\frac{\lambda}{n}$. Hence $\underline{p}_{j}=l_{j}^{\tau}$;

(vi). Suppose not, i.e., suppose there is an interval $\left[p_{l}, p_{h}\right]$ satisfying $l_{j}^{\tau} \leq p_{l}<p_{h} \leq 1$ such that $F\left(p_{l}\right)=F\left(p_{h}\right)$. Suppose also that $p_{l}$ is the infimum of all prices $p, l_{j}^{\tau} \leq p \leq 1$. Then $p_{l}$ is in the support of $F(\cdot)$ and, from (ii) $\Pi_{j}^{\star}=\Pi_{j}\left(p_{l}\right)=p_{l} \frac{\lambda}{n}+p_{l}(1-\lambda) \phi_{j}^{\tau}\left[1-F\left(p_{l}\right)\right]^{k-1}<$ $p_{h} \frac{\lambda}{n}+p_{h}(1-\lambda) \phi_{j}^{\tau}\left[1-F\left(p_{h}\right)\right]^{k-1}=\Pi_{j}\left(p_{h}\right)$, a contradiction.

Proof of Proposition 1. We show constructively that equilibrium exists. Alternatively, existence follows from theorem 5 of Dasgupta and Maskin (1986). (i) Use Lemma 1(iv) to set $\Pi_{j}(p)=p \frac{\lambda}{n}+p(1-\lambda) \phi_{j}^{\tau}[1-F(p)]^{k-1}=\frac{\lambda}{n}$. Solving for $F(p)$ the result follows; (ii) Obvious.

Proof of Remark 1. (i) Follows from the fact that all firms are indifferent between any equilibrium price and the monopoly price. (ii) Follows directly from the definition of $\mu^{c}=$ $l^{c}+\int_{l^{c}}^{1}\left(1-F^{c}\right)^{n} d p$ and $\varepsilon^{c}=l^{c}+\int_{l^{c}}^{1}\left(1-F^{c}\right) d p$.

Theorem 1. (i) $\varepsilon^{c}(n)<\varepsilon^{c}(n+1)$; (ii) $\mu^{c}(n)>\mu^{c}(n+1)$.

Proof of Theorem 1. (i) See Morgan et al. (2006); (ii) Follows from (i) and Remark 1(i). $\square$

Proof of Corollary 1. Obvious.

Proof of Proposition 2. (i) Obvious; (ii) Follows from Corollary 1 and the Theorem 1; (iii) Obvious.

Proof of Corollary 2. (i) Obvious; (ii) Follows from Corollary 1 and the Theorem 1.

Proof of Proposition 3. (i) Obvious; (ii) Follows from (i); (iii) Obvious; (iv) Follows from (iii).

Proof of Corollary 3. (i) Obvious; (ii) Obvious; (iii) Follows from (ii); (iv) Follows from (ii). 


\section{APPENDIX B. INSTRUCTIONS FOR SUBJECTS (TRANSLATED FROM SPANISH)}

- The purpose of this experiment is to study how subjects take decisions in specific economic contexts. This project has received financial support by public funds. Your decision making in this session is going to be of great importance for the success of this research. At the end of the session you will receive a quantity of money in cash which will depend on your performance during the session.

- The environment in which the experiment takes place is an industry. This industry has the following characteristics:

(a) a price comparison search platform like the ones on the Internet,

(b) 3 firms, (Treatments 4-8: 6 firms),

(c) 1,200 consumers.

Each firm in the industry produces a homogeneous product, and this product is the same for all firms.

- Transactions will take place in UMEX (our lab's Experimental Monetary Units).

- This session will consist of 50 rounds.

- You are one of the 3 firms (Treatments 4-8: 6 firms) in the industry. Your production costs are zero. Therefore, your profits are equal to your revenue.

- Each round, you and the rest of the firms in the industry have to decide the price at which you want to sell the product. Price is your only decision variable.

- (Treatments 1 and 4) Each period, a Price search platform lists the prices of all firms in the industry.

- (Treatments 2, 5 and 7) Each period, a Price search platform lists the prices of 2 firms (Treatment 5: 4 firms) in the industry. More precisely, each round, the price comparison search platform randomly chooses 2 firms (Treatment 5: 4 firms), whose price will be included in its price list. The identity of the firms whose price will be included in the list of the price search platform, will be announced publicly to the members of the industry after the firms' prices are posted.

- (Treatments 3, 6 and 8) Each period, a Price search platform lists the prices of 2 firms (Treatment 6: 4 firms) in the industry. More precisely, each round, the price comparison search platform randomly chooses 2 firms (Treatment 6: 4 firms), whose price will be included in its price list. The identity of the firms whose price will be included in the list of the price search platform, will be announced publicly to the members of the industry before the firms' prices are posted.

- Each consumer wants to buy one unit of the product per round. The maximum willingness to pay of each consumer for a unit of the product is 1,000 UMEX. That is, if the price you fix is higher than 1,000 UMEX, nobody will buy from you. 
- There are two types of consumers. Half of them, i.e., 600 consumers, will read the list of price created by the search platform. The other half do not actually read the list of prices of the search engine (maybe because they are not able to do so).

- The consumers who read the price list of the search platform will buy, each period, from the firm whose price for that period is the lowest among all prices included in the price list, if such price does not exceed 1,000 UMEX. In case of a "tie" (i.e., several firms fix the same minimum price) the consumers are distributed evenly among the firms with the same minimum price.

- The consumers who do not read the search platform's price list will buy "randomly" from any vendor, so that this group of consumers will be distributed evenly among all firms in the industry.

- In each round, 3 firms (Treatments 4-8: 6 firms) forming (together with you) the same industry, will be randomly drawn among the 18 participants of this session. Therefore, the probability of competing with the same 2 firms (Treatments 4-8: 5 firms) in 2 different periods is very low (less than $10 \%$ ).

- Once the participants have been assigned to the industries, you must set your price. The master program in the computer will simulate the consumers' reactions. At the end of each round, you will see on your screen the information about your own sales, your earnings and the prices fixed by your competitors in the market.

- At the end of the session you will be paid in cash. Your reward will be determined taking into account the earnings you accumulate over 10 (randomly selected) out of the total 50 periods. The exchange rate will be: $1,000,000 \mathrm{UMEX}=10 €$.

Thank you very much for your participation. Good luck!

\section{REFERENCES}

[1] Armstrong, M., Vickers, V., Zhou, J., 2009. Prominence and consumer search. RAND Journal of Economics 40(2), pp. 209-233.

[2] Arnold, M., Li, C., Saliba, C., Zhang, L., 2011. Asymmetric market shares, advertising, and pricing: Equilibrium with an information gatekeeper. Journal of Industrial Economics 59(1), pp. 63-84.

[3] Athey, S., Ellison, G., 2011. Position Auctions with Consumer Search. Quarterly Journal of Economics, 126(3), pp. 1213-1270.

[4] Bagwell, K., Lee, G., 2012. Number of firms and price competition. mimeo.

[5] Baye, M., Kovenock, D., Devries, C., 1992. It takes two to tango: Equilibria in a model of sales. Games and Economic Behavior 4, pp. 493-510.

[6] Baye, M., Morgan, J., 2001. Information gatekeepers on the Internet and the competitiveness of homogeneous product markets. American Economic Review 91(3), pp. 454-474. 
[7] Benaïm, M., Hofbauer, J., Hopkins, E., 2009. Learning in games with unstable equilibria. Journal of Economic Theory 144, pp. 1694-1709.

[8] Bradlow, E., Schmittlein, D., 1999. The little engine that could: Modeling the performance of world wide web search engines. Marketing Science 19(1), pp. 43-62.

[9] Brown, J., Goolsbee, A., 2002. Does the Internet make markets more competitive? Evidence from the life insurance industry. Journal of Political Economy, 110(3), pp. 481-507.

[10] Brynjolfsson, E., Smith, M., 2000. Frictionless commerce? A comparison of Internet and conventional retailers. Management Science 46(4), pp. 563-585.

[11] Burdett, K., Judd, K., 1983. Equilibrium price dispersion. Econometrica 51, pp. 955-969.

[12] Cason, T.N., Datta, S., 2006. An experimental study of price dispersion in an optimal search model with advertising. International Journal of Industrial Organization 24, pp. 639-665.

[13] Cason, T.N., Friedman, D., 2003. Buyer search and price dispersion: A laboratory study. Journal of Economic Theory 112, pp. 232-260.

[14] Chen, Y., Riordan, M., 2008. Price-increasing competition. RAND Journal of Economics 39(4), pp. 1042-1058.

[15] Clay, K., Krishnan, R., Wolff, E., Fernandes, D., 2002. Retail Strategies on the Web: Price and Non-Price Competition in the Online Book Industry. The Journal of Industrial Economics 50(3), pp. 351-367.

[16] Clemons, E., Hann, I., Hitt, L., 2002. Price dispersion and differentiation in online travel: an empirical investigation. Management Science 48(4), pp. 534-549.

[17] Corniere, A. and Taylor, G., 2012. Integration and search engine bias. mimeo.

[18] Dahlby, B., West, D., 1986. Price dispersion in an automobile insurance market. Journal of Political Economy 94(2), pp. 418-438.

[19] Dasgupta, P., Maskin, E., 1986. The existence of equilibrium in discontinuous economic games, I: Theory. Review of Economic Studies 53, pp. 1-26.

[20] De los Santos, B., Hortacsu, A., Wildenbeest, M., 2013. Testing models of consumer search behavior using data on web browsing and consumer purchases. American Economic Review 102(6), pp. 2955-2980.

[21] Dinlersoz, E., Pereira, P., 2007. On the diffusion of electronic commerce. International Journal of Industrial Organization 25(3), pp. 541-574.

[22] Ellison, G., Wolitzky, A., 2009. A search cost model of obfuscation. RAND Journal of Economics 45(3), pp. 417-441.

[23] Ellison, G., Ellison, S., 2009. Search, Obfuscation, and Price Elasticities on the Internet. Econometrica 77(2), pp. 427-452. 
[24] Fischbacher U., 2007. z-Tree: Zurich toolbox for readymade economic experiments. Experimenter's manual. Experimental Economics 10(2), pp. 171-178.

[25] Fonseca, M.A., Normann, H.T., 2008. Mergers, asymmetries and collusion: Experimental evidence. The Economic Journal 118, pp. 387-400.

[26] Frank, R., Salkever, D., 1997. Generic entry and the market for pharmaceuticals. Journal of Economic and Management Strategy 6, pp. 75-90.

[27] García-Gallego, A., Georgantzís, N., Jaramillo-Gutiérrez, A., Pereira, P., Pernías, J.C., 2014. Monopolistic Product Line Competition with Ex Post Consumer Heterogeneity. Journal of Business Research 67(5), pp. 795-801.

[28] Grabowski, H., Vernon, J., 1992. Brand loyalty, entry and price competition in pharmaceuticals after the 1984 Drug Act. Journal of Law and Economics 35, pp. 331-350.

[29] Guimarães, P., 1996. Search intensity in oligopoly. Journal of Industrial Economics 44, pp. 415-426.

[30] Hagiu, A., Jullien, B., 2011. Why do intermediaries divert search? RAND Journal of Economics 42(2), pp. 337-62.

[31] Harrison, G., Morgan, P., 1990. Search intensity in experiments. Economic Journal, 100, pp. 478-486.

[32] Hopkins, E., Seymour, R., 2002. The stability of price dispersion under seller and consumer learning. International Economic Review 43, pp. 1157-1190.

[33] Huck, S., Normann, HT., Oechssler, J., 2004. Two are few and four are many: Number effects in experimental oligopolies. Journal of Economic Behavior and Organization 53, pp. 435-446.

[34] Iyer, G., Pazgal, A., 2000, Internet shopping agents: Virtual co-location and competition. Marketing Science 22, pp. 85-106.

[35] Janssen, M.C.W., Moraga-González, J.L., 2004. Strategic pricing, consumer search and the number of firms. Review of Economic Studies 71, pp. 1089-1118.

[36] Lach, S., 2002, Existence and persistence of price dispersion: an empirical analysis, The Review of Economics and Statistics, 84(3), pp. 433-444.

[37] Lawrence, S., Giles, C., 1998. Searching the world wide web. Science 280(3), pp. 98-100.

[38] Lawrence, S., Giles, C., 1999. Accessibility of information on the web. Nature 400, pp. 107-109.

[39] Montgomery, A., Hosanagar, K., Krishnan, R., Clay, K., 2004. Designing a better shopbot. Management Science 50(2), pp. 189-206.

[40] Morgan, J., Orzen, H., Sefton, M., 2006. An experimental study of price dispersion. Games and Economic Behavior 54, pp. 134-138. 
[41] Orzen H., 2008. Counterintuitive number effects in experimental oligopolies. Experimental Economics 11(4), pp. 390-401.

[42] Orzen, H., Sefton, M., 2008. An experiment on spatial price competition. International Journal of Industrial Organization 26, pp. 716-729.

[43] Pereira, P., 2005. Do lower search costs reduce prices and price dispersion?. Information Economics and Policy 17(1), pp. 61-72.

[44] Rosenthal, R., 1980. A model in which an increase in the number of sellers leads to a higher price. Econometrica 48, pp. 1575-1579.

[45] Samuelson, L., Zhang, J., 1992. Search costs and prices. Economics Letters 38, pp. 55-60.

[46] Schotter, A., Braunstein, Y., 1981. Economic search: An experimental study. Economic Inquiry 19(1), pp. 1-25.

[47] Seade, J., 1980. On the effects of entry. Econometrica 48(2), pp. 479-489.

[48] Sorensen, A., 2000. Equilibrium price dispersion in retail markets for prescription drugs. Journal of Political Economy, 108(4), pp. 833-850.

[49] Stahl, D., 1989. Oligopolistic pricing with sequential consumer search. American Economic Review 79, pp. 700-712.

[50] Stigler, G., 1961. The economics of information. Journal of Political Economy 69(3), pp. 213-225.

[51] Tang, Z., Smith, M., Montgomery, A., 2010. The impact of shopbot use on prices and price dispersion: Evidence from online book retailing. International Journal of Industrial Organization 28, pp. 579-590.

[52] Varian, H., 1980. A model of sales. American Economic Review 70, pp. 651-659.

[53] White, A., 2013. Search engines: Left side quality versus right side profits. International Journal of Industrial Organization 31(6), pp. 690-701. 